\title{
Multifractal Analysis of the Foreign Exchange Markets Application to MENA Countries
}

\author{
Nabiha Haouas ${ }^{1}$ \\ ${ }^{1}$ University of Sousse, FSEG SOUSE Tunisia \\ Correspondence: Nabiha Haouas, University of Sousse, Tunisia. \\ Received: March8, 2021 \\ Accepted: April 10, 2021 \\ Online Published: April 19, 2021 \\ doi:10.5430/afr.v10n2p17 \\ URL: https://doi.org/10.5430/afr.v10n2p17
}

\begin{abstract}
The present study focus on the multifractal analysis of the exchange rate for Middle East North Africa (MENA) region from January 1999 to May 2017. The purpose of this paper is to examine the behavior of currency markets and to verify the efficiency hypothesis of FOREX market for these countries. We first estimate the scaling function to detect the multifractal character of each series and then the Hölder exponent, using the Generalized Quadratic Variation $(\mathrm{GQV})$ method, as a function of time $\mathrm{H}(\mathrm{t})$. We conclude that there's a multifractal character for all these countries with a difference in the degree of persistence of each market.
\end{abstract}

Keywords: efficiency of exchange markets, fractal markets hypothesis, multifractal, hurst exponent, exchange rate, MENA

\section{Introduction}

The foreign exchange market is characterized by the absence of geographic and temporal boundaries. It indicates the place of meeting between the supply and the demand for foreign currency and it constitutes the most important of all financial markets in terms of volume of transactions. Thus the evolution of the exchange rate is a concern which does not cease to grow both for policymakers and for the economists. In effect, their decisions support, mostly, on this macroeconomic variable which fits in a complex environment, fluctuating and uncertain. From an economic point of view, the instability of exchange rates is a significant characteristic of the current global economy and it has a great importance in the debate world economy saw its strategic role in the economic stabilization. For this reason, several economists have looked on the modeling of the exchange rate, which has also known many developments. There is an impressive diversity of theories and techniques that attempt to respond to the variety of tasks of economic analyzes around the world. Whereas, the empirical literature shows that it is difficult to predict and explain the fluctuations of the exchange rate since the analysis of these fluctuations is linked to that of economic fluctuations which generally fall within the framework stochastic. The direct involvement of such an observation is that a linear unpredictability well describes the series of exchange rates in high frequency.

However, the instability of exchange rates, as well as the emergence of speculative bubbles, seems to indicate that this market is not efficient. Indeed, the hypothesis of the efficiency of markets (efficient market hypothesis 'EMH') has been formulated for the first time in the United States by Eugene Fama in its founding articles at the beginning of the sixties, see Fama (1965). This theory assumes that the price of the shares is unpredictable and follows a random walk, i.e. that the price includes the whole of the available information (past, present and future). No investor may succeed in obtaining a profit abnormal on the market for a certain level of risk given. Intuitively, a forecast profitable is impossible for the actors of the market thus leading to the efficiency of the market. Since the hypothesis of efficient markets based the essential work orthodox and several researchers are interested in the subject. The quantity the theoretical and empirical work carried out on this theme is truly impressive, including one of the most famous is that of Malchiel (1973). It is as well that over the time, none of the proposals set out by the economic science has found empirical support also massif. As a result of this proposal, a distinction is made between those for which this assumption remains largely verified, see Fama $(1970,1991)$ and those for which the evidence of inefficiency is sufficient for the question, see Jensen (1978), Shleifer (2010), and Malchiel (2003). In fact, during the recent financial crisis, several failures and different questions emerged of this theory. This is the subject of several problems of internal consistency and continues to feed abundant literature which contains a whole series of controversies. See, Yen et al. (2008) and Lim (2011). 
The alternative is the Fractal Market Hypothesis (FMH), introduced by Peters (1994), was founded as a function of the most general features of the markets. The FMH derives its name from the theory of fractals. A fractal is a mathematical object characterized by two properties; it is constructed by an iterative process and presents a character of self-similarity. As well, taking into account the invariant character at all time scales, the schema that could have been highlighted reproduces as well on a unit of time in a year, a month, a week, a day or an hour, etc. It can expect developments absolutely identical to this property of the invariance of the timescale.

In addition, when the markets are stable, the yields calculated on different scales of time (daily, weekly, monthly, etc.) have the same structure of autocovariance. Therefore, it is suggested that the financial markets have a fractal structure. In the literature, the FMH is generally linked to the detection of the fractality or the multifractality processes of financial asset prices see the work of Peters (1994), Onali et al. (2009, 2011). However, it has not been put to the test about the foreign exchange market. The purpose of this paper is to expose the multifractal formalism in order to present the FMH to examine the behavior of exchange markets for the MENA countries. The article is organized as follows. In section 2, we present the specific tools to the multifractal modeling of the exchange rate series. Then, in section 3, we perform an empirical application on the exchange rate of the MENA countries, against the euro, in detecting the multifractality of these series and estimating the Hurst exponent associated.

\section{Multifractal Formalization}

The fractal models have long been neglected in quantitative finance in favor of the diffusion process, which is based on the Brownian motion (the continuous time of the random walk). The Brownian motion is a member of the class of processes with continuous trajectories and stationary increases that are independent of the past. The fact that the increases are independent implies that we cannot beat the market, that is, one cannot predict the movements of the market by using past data. The fact that the increases are stationary Gaussian implies that one accepts a Gaussian modeling of the volatility. This tool will be therefore ideal for modeling the random part of the evolution of an asset on the market. The most well-known model is the Black and Scholes model (B\&S), which models the trajectories of price as an exponential of Brownian motion. These fractal type processes have not been used in finance until the 1990s because of problems related to the concept of the arbitrage opportunity. In effect, it is not evident that even if arbitration is present, one could still exploit it positively. Since a large number of empirical studies have been devoted to study the question of search arbitrage opportunities and to test the limits of the EHH, which has been tested and subjected to constant critical review. Recently, Guasoni et al. (2008) have shown that if there are proportional transaction costs at a rate, then the fractal processes are an eligible model in finance i.e. that there is no arbitrage opportunity for fractal type processes. In the literature, the work of Peters (1994), Fillol (2003) and Onali et al. $(2009,2011)$ studied the detection of the fractality or multifractality of financial asset price processes generally related to the FMH.

\subsection{Reminder of Fractional Brownian motion (FBM) and Multifractional (MBM)}

The FBM was introduced by Kolmogorov in the 40s and then popularized by Mandelbrot in 1968; it has been used to model the natural phenomena in hydrology and finance. A standard FBM:

$$
B_{H}=\left(B_{H}(t), t \in \mathfrak{R}_{+}\right)
$$

is a Gaussian process centered structure, with $H \in(0,1)$, whose covariance structure is given by:

$$
\forall(t, s) \in \mathfrak{R}^{2} E\left(B_{H}(t), B_{H}(s)\right)=\frac{V_{H}}{2}\left(|t|^{2 H}+|s|^{2 H}-|t-s|^{2 H}\right)
$$

With:

$$
V_{H}=\Gamma(1-2 H) \frac{\cos (\Pi H)}{\Pi} .
$$

This process is characterized by its Hurst parameter $\mathrm{H}$ which drives the three following properties:

- The roughness of the path is $\mathrm{H}$, where the pointwise is defined by:

$$
\alpha_{X}^{*}(t)=\sup \left\{\alpha, \limsup _{h \rightarrow 0} \frac{|X(t+\varepsilon)-X(t)|}{\varepsilon^{\alpha}}=0\right\}=H, \text { for all } t \in R ;
$$


- The self-similarity of order

$$
H:\left(B_{H}(\alpha t)\right)_{t \in \Re} \stackrel{(d)}{=}\left(\alpha^{H} B_{H}(t)\right)_{t \in \Re \text { for all }} \alpha>0 ;
$$

- The correlation of the increases is of order $\frac{1}{n^{2-2 H}}$.

When the Hurst index $H=1 / 2$, is the well-known Brownian motion (corresponds to the assumption of the efficiency of markets (Efficient Markets Hypothesis EMH)). For this reason, $\mathrm{fBm}$ appears as a generalization of the Brownian motion. This $\mathrm{fBm}$ has been intensively used in the modeling of random phenomena; however, for the sample path properties of $\mathrm{fBm}$, it has continuous trajectories and the value of the Hurst parameter $\mathrm{H}$ decides the regularity of sample paths. Hence, it was suggested that the parameter $\mathrm{H}$ must be allowed to vary as a function of time for modeling such data. However, an extension of the fBm has been proposed by Benassi et al. (1997) and Peltier et al. (1995). It is called multi-fractional Brownian motion ( $\mathrm{mBm})$. The $\mathrm{mBm}$ can be defined follows:

$$
\mathrm{B}_{\mathrm{H}_{\mathrm{t}}}(\mathrm{t})=\int_{-\infty}^{+\infty} \frac{\mathrm{e}^{\mathrm{it} \xi}}{|\xi|^{\mathrm{H}_{\mathrm{t}}+\frac{1}{2}}} \mathrm{dW}(\xi),
$$

Where $\mathrm{dW}(\xi)$ is a Brownian measure. This process is characterized by its Holder function $\mathrm{H}(\mathrm{t})$, with values in ]0,1[. To summarize, the $\mathrm{mBm}$ is a continuous Gaussian process centered whose pointwise holder exponent can be prescribed and evolves with time $t$. As the Holder exponent of the $\mathrm{fBm}$ is equal to its Hurst index, the natural idea is to replace the Hurst index $\mathrm{H}$ by a function of the time $\mathrm{H}(\mathrm{t})$ in one of the representations of $\mathrm{fBm}$. These different constructs lead to the same process, see Ayache et al. (2005).

\subsection{Estimating Hurst index}

Actually, many estimators for the Hurst parameter have been proposed, based for example on time domain methods or spectral methods. A good survey can be found in Coeurjolly (2001) and Bertrand et al. (2010). Given the fact that the Hurst index corresponds to the roughness of the path, the idea of Guyon and Leon (1989), is to measure it by the quadratic variation. We refer here to the most popular estimator; Generalized Quadratic Variations (GQV), see Istas et al. (1997). Consider a series of size $\mathrm{n}$, the estimator of the Hurst exponent by the GQV is given by:

$$
\hat{H}_{G Q V}=\frac{1}{2}\left(1+\log _{2} \frac{V_{N} / 2}{V_{N}}\right)
$$

With $V_{N}$, is the Generalized Quadratic Variations defined by:

$$
V_{N}=\sum_{k=1}^{N}\left|X\left(\frac{k+1}{N}\right)-2 X\left(\frac{k}{N}\right)+X\left(\frac{k-1}{N}\right)\right|^{2}
$$

\section{Application}

\subsection{Presentation of Data}

The sample under consideration in this paper consists of verifying the efficiency hypothesis of FOREX markets in the Middle East North Africa region (MENA). We retain a dataset period spanning over January 1999 to May 2017 (6721 daily observations), for 20 countries namely: Algeria, Saudi Arabia, Bahrain, Djibouti, Egypt, United Arab Emirates, Ethiopia, Iran, Iraq, Israel, Jordan, Kuwait, Lebanon, Libya, Mauritania, Morocco, Qatar, Sudan, Syria, Tunisia. All data were extracted from the websites investing. This choice is motivated by the fact that these countries located between Europe, Africa and Asia had a privileged geographical situation and diversified whose potential for development has not yet been released. In addition, this region characterized by an economic dynamism allowing a diversified investment since it has both prosperous oil economies of the Gulf and of resources in developing countries compared to their population, such as Egypt, Morocco, and Yemen. 


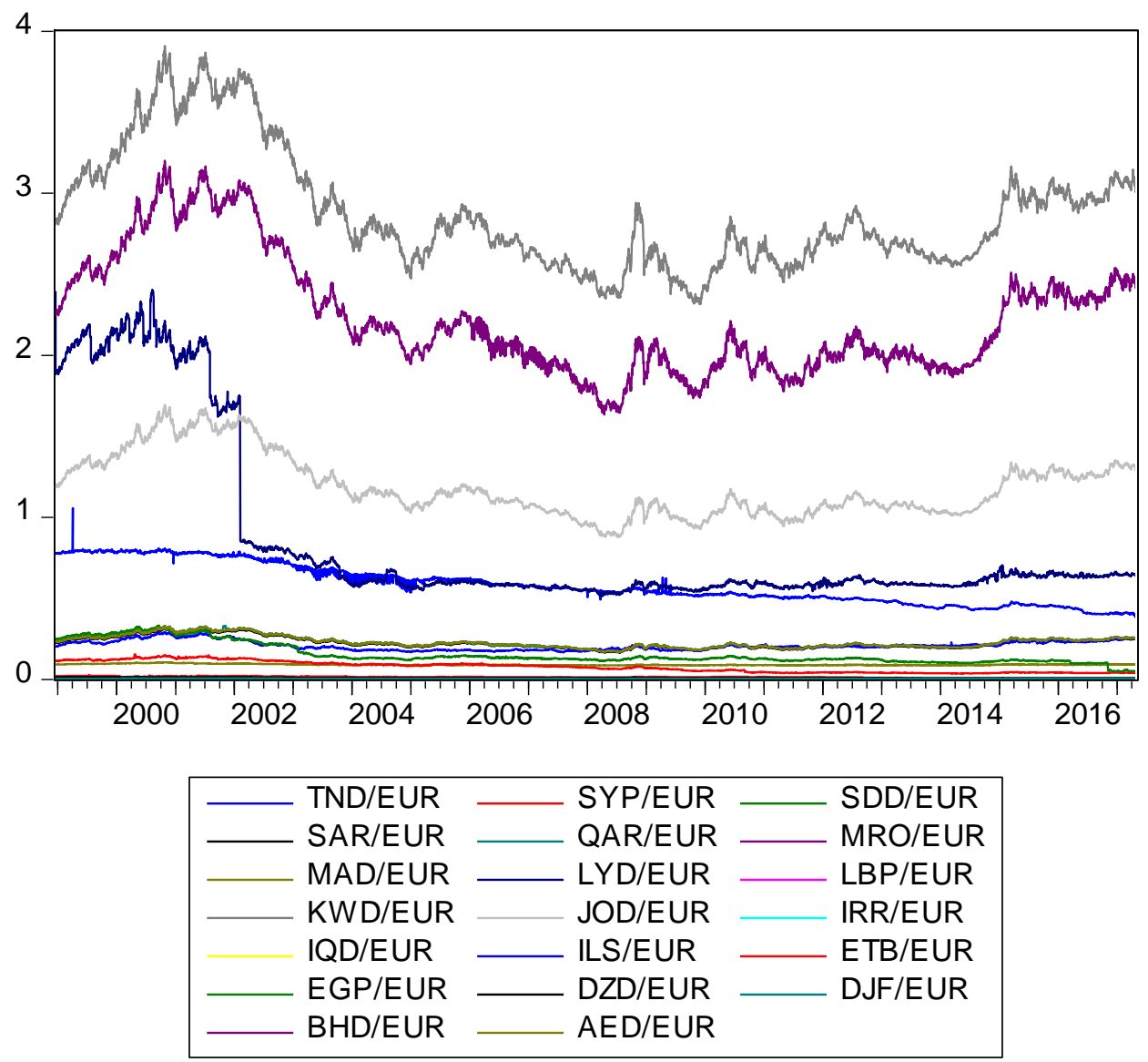

Figure 1. Evolution of the exchange rate for the countries MENA compared to the euro for the period running from January 1999 to May 2017.

The whole of these sets of rates of exchange is an instrument to measure the behavior of markets and it is considered as a synthetic data reflecting the overall evolution of the countries MENA. It seems that the fluctuations of exchange rates, particularly for Kuwait, Bahrain, Jordan and Libya are often more than what the other countries of the MENA. However, they happen to be excessively unstable and their fluctuations have sometimes caused severe disruptions and make real loads on the economy.

The Table 1 refers some statistical indicators, namely: the mean, the coefficient of asymmetry (skewness), the coefficient of flattening (Kurtosis) and the estimated value of the Statistics Jarque-Bera for the 20 sets of rates of exchange of the countries MENA.

Table 1. Descriptive Exchange Rate Statistics for MENA Countries

\begin{tabular}{lclll}
\hline & Mean & Skewness & Kurtosis & Jarque-Bera \\
\hline TND /EUR & 0.5829 & 0.4851 & 2.0313 & 526.3255 \\
SYP/EUR & 0.0137 & -0.4681 & 2.3358 & 368.9720 \\
SDD/EUR & 0.0029 & -0.410 & 2.0053 & 464.6258 \\
SAR/EUR & 0.2254 & 0.8195 & 2.8048 & 762.9870 \\
QAR/EUR & 0.2320 & 0.8306 & 2.8289 & 781.0380 \\
MRO/EUR & 0.0031 & 1.1708 & 2.9617 & 1535.9780 \\
MAD/EUR & 0.0913 & 1.4017 & 4.4631 & 2800.3612 \\
LYD/EUR & 0.8550 & 1.7644 & 4.2872 & 3951.4156 \\
LBP/EUR & 0.0005 & 0.8479 & 2.8637 & 810.6124
\end{tabular}




$\begin{array}{lllll}\text { KWD/EUR } & 2.8763 & 0.9793 & 3.1664 & 1082.0373 \\ \text { JOD/EUR } & 1.1869 & 0.8139 & 2.7984 & 753.4695 \\ \text { IRR/EUR } & 0.0002 & 1.6895 & 4.0446 & 3502.9800 \\ \text { IQD/EUR } & 0.0006 & -0.6551 & 2.8069 & 491.1208 \\ \text { ILS/EUR } & 0.2093 & 0.7744 & 2.7821 & 684.9942 \\ \text { ETB/EUR } & 0.0765 & 0.4046 & 1.8092 & 580.4283 \\ \text { EGP/EUR } & 0.1553 & 1.2451 & 3.2868 & 1759.6500 \\ \text { DZD/EUR } & 0.0108 & 0.8047 & 2.5514 & 781.7716 \\ \text { DJF/EUR } & 0.0047 & 0.9389 & 2.9082 & 989.8138 \\ \text { BHD/EUR } & 2.2334 & 0.8323 & 2.8158 & 785.4551 \\ \text { AED/EUR } & 0.2301 & 0.8197 & 2.8033 & 763.4329\end{array}$

In the Table 1, we find that the coefficient of kurtosis, for 15 sets of rates of exchange, is lower than the value of the kurtosis of the normal law, which is equal to 3. While for the other five series, namely: Kuwait, Egypt, Iran, Libya and Morocco, it is a little high. This indicates that the curve of the series of the rate of exchange is more flattened that the curve of ordinary law. We note, moreover, that the coefficient of skewness is always different from zero, which shows the presence of the asymmetry of all curves of the exchange rate. This leads us to reject the null hypothesis that the data comes from a normal distribution for all exchange rate of MENA countries. The Jaque-Béra test confirms this result.

\subsection{Detection of Multifractality}

We will now look at the methodology for detecting multifractality of the exchange rate. A simple method and specific to identify and study the multifractal character of the series while taking into account the known properties of these financial series can be found in the work of Mandelbrot et al. (1997) and Calvet et al. (2002) which allow you to determine if the process is multifractal or not.

Either $P(t)$ the series of price $t \in[0, T]$ and dividing $\mathrm{T}$ In $\mathrm{n}$ Sub-length intervals $\Delta t$, the partition functions will be the following:

$$
S_{q}(\Delta t)=\sum_{j=0}^{N-1}|X(j+1) \Delta t-X(j \Delta t)|^{q}
$$

By definition of multifractality, a stochastic process $X(t)$ is multifractal if its increments are stationary and satisfied:

$$
E\left\{X(t+\Delta t)-\left.X(t)\right|^{q}\right\}=c(q)(\Delta t)^{\tau(q)+1}
$$

For all $\Delta t \in T, q \in Q$

Where $\mathrm{t}$ and $\mathrm{Q}$ are intervals of $\mathrm{R}, \tau(q)$ and $c(q)$ functions are defined on $\mathrm{Q}$.

Which implies;

$$
\ln \left\{E\left(S_{q}(\Delta t)\right)\right\}=\tau(q) \ln (\Delta t)+c(q) \ln (T)
$$

When the $q^{\text {th }}$ time is there. This means that the logarithm of the sums will be linear to the logarithm of $\Delta t$.

Is called the scaling function of the multifractal process, it is the principal tool to detect the multifractal character of a series. In effect, if the scaling function is linear, the process is uni-fractal while a $\tau(q)$ non-linear function involves a multifractality, see, UM (1999). The methodology is to estimate. for a first time, the multifractal spectrum in the middle of the partition function $S_{q}(\Delta t)$ and the scaling function $\tau(q)$ for the 20 sets of rates of exchange. 

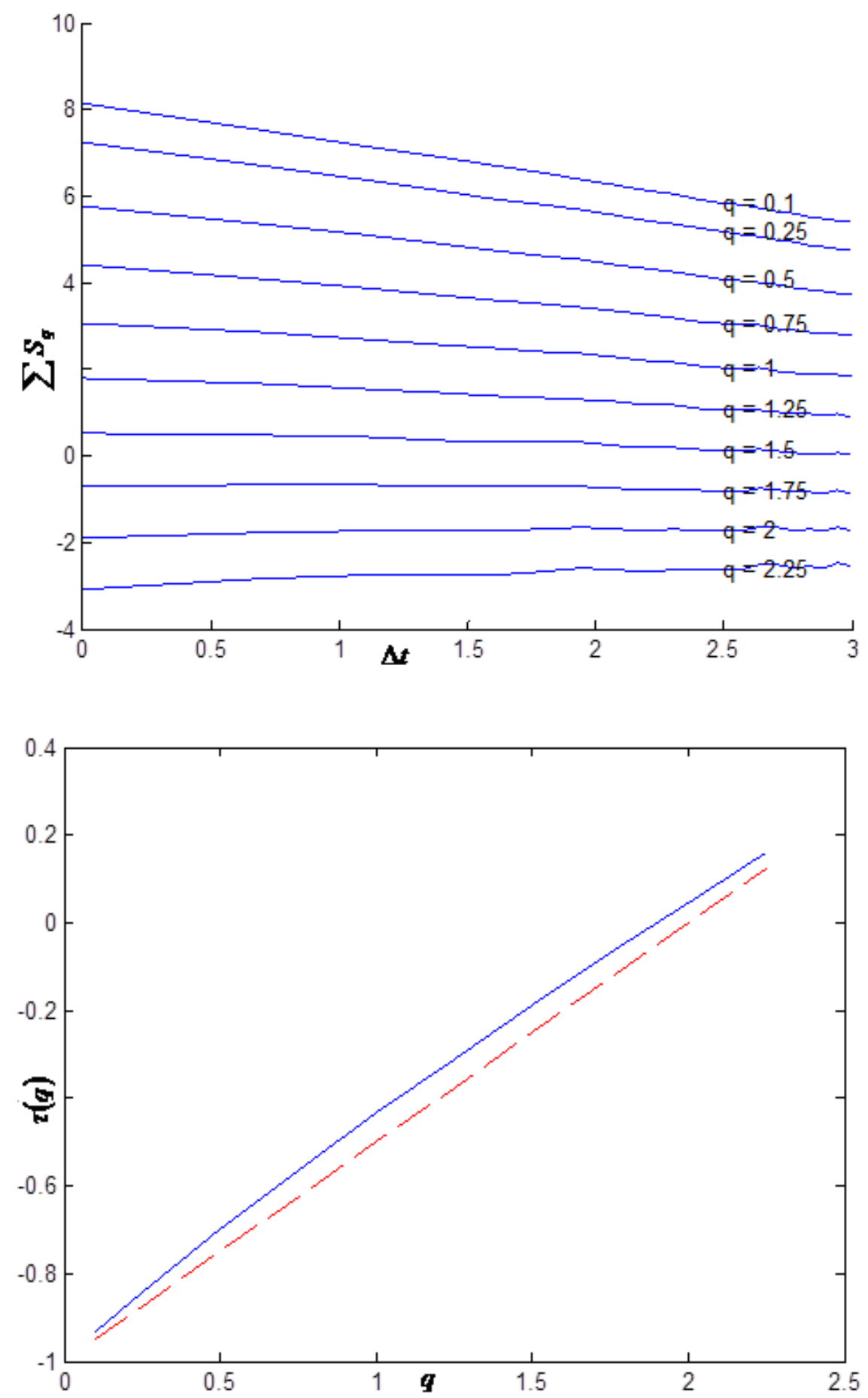

Figure 2. The Partition Function and Scaling Function for the AED/EUR exchange rate 

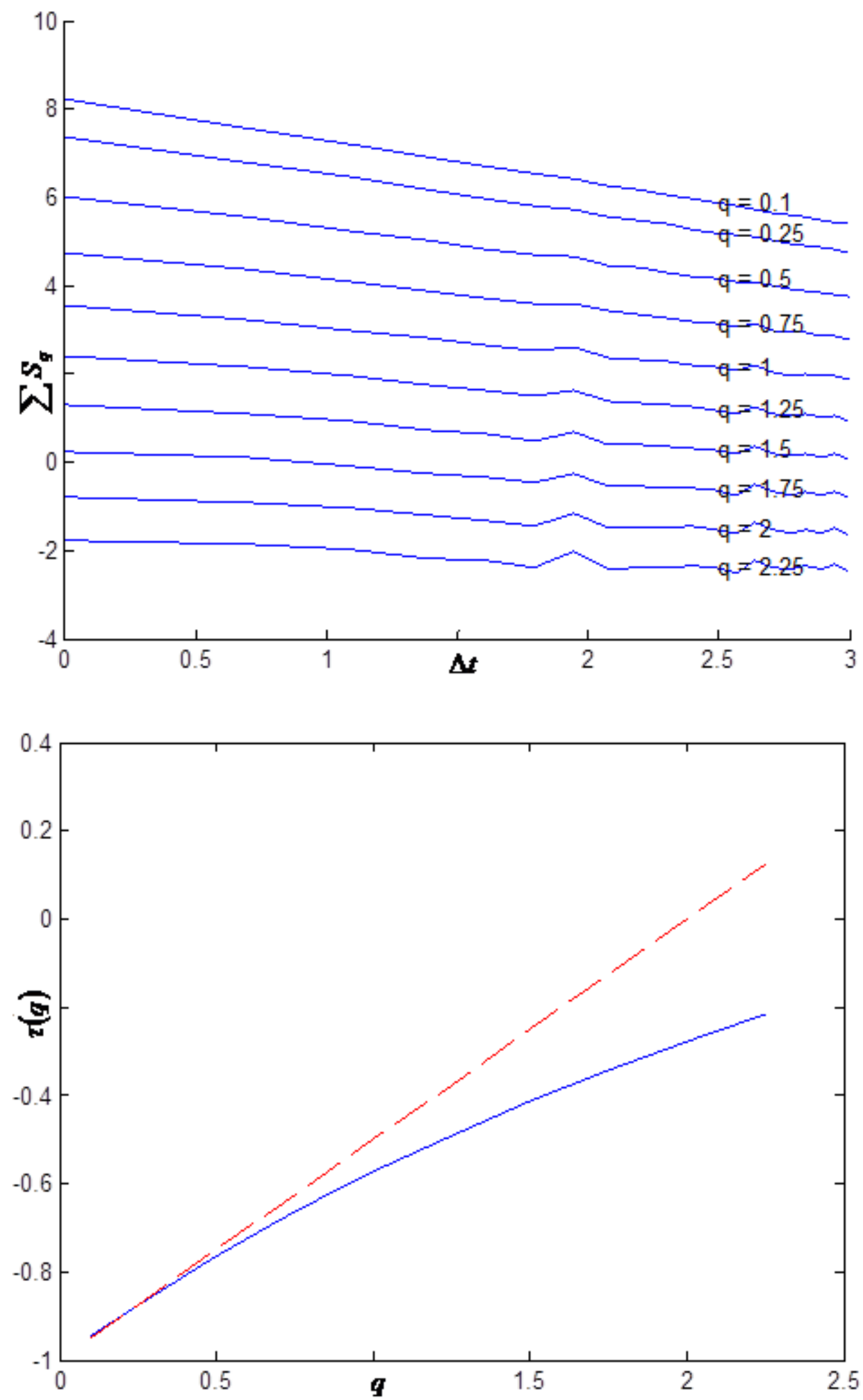

Figure 3. The Partition Function and Scaling Function for the BHD/EUR exchange rate 

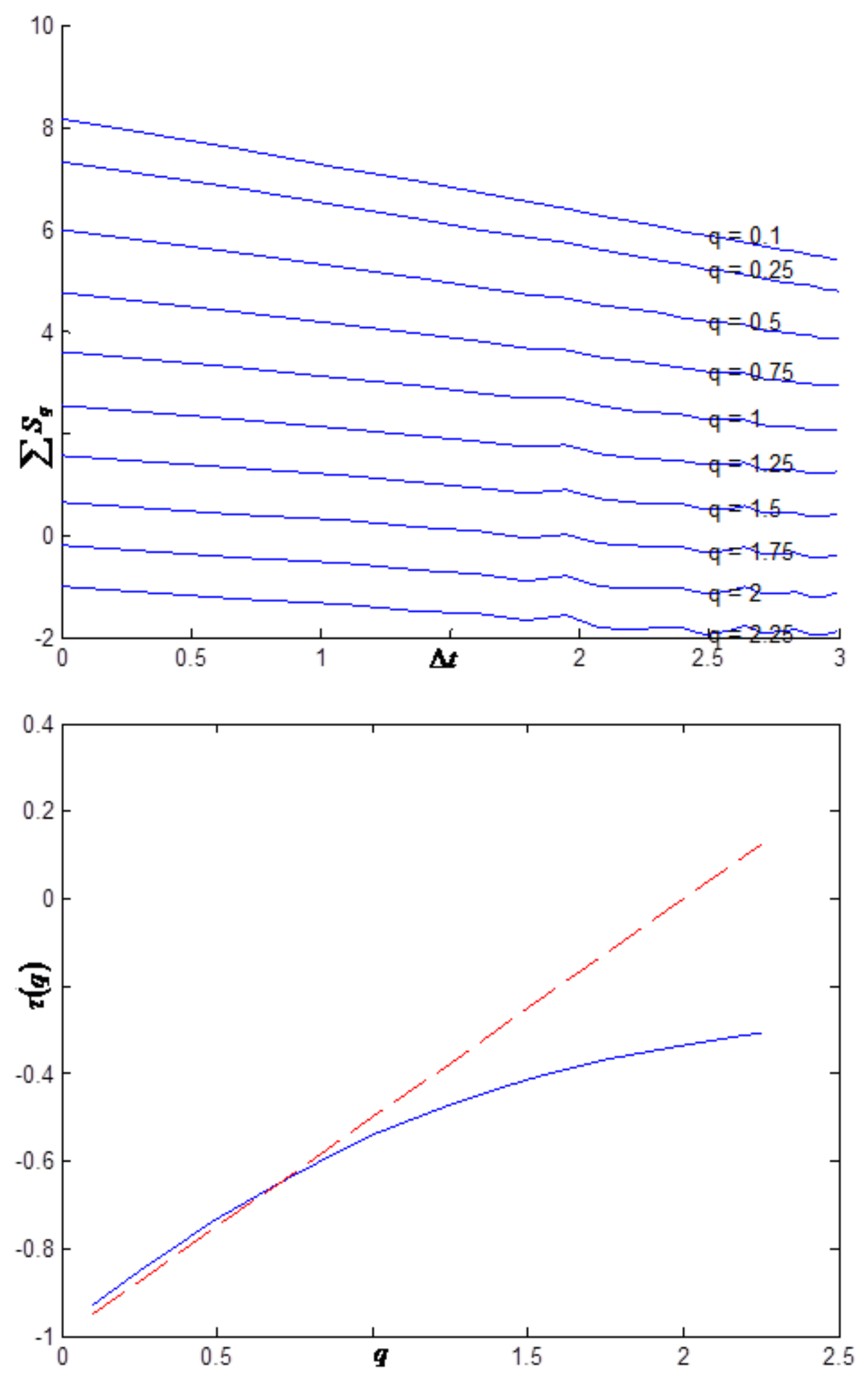

Figure 4. The Partition Function and Scaling Function for the DJF/EUR exchange rate 

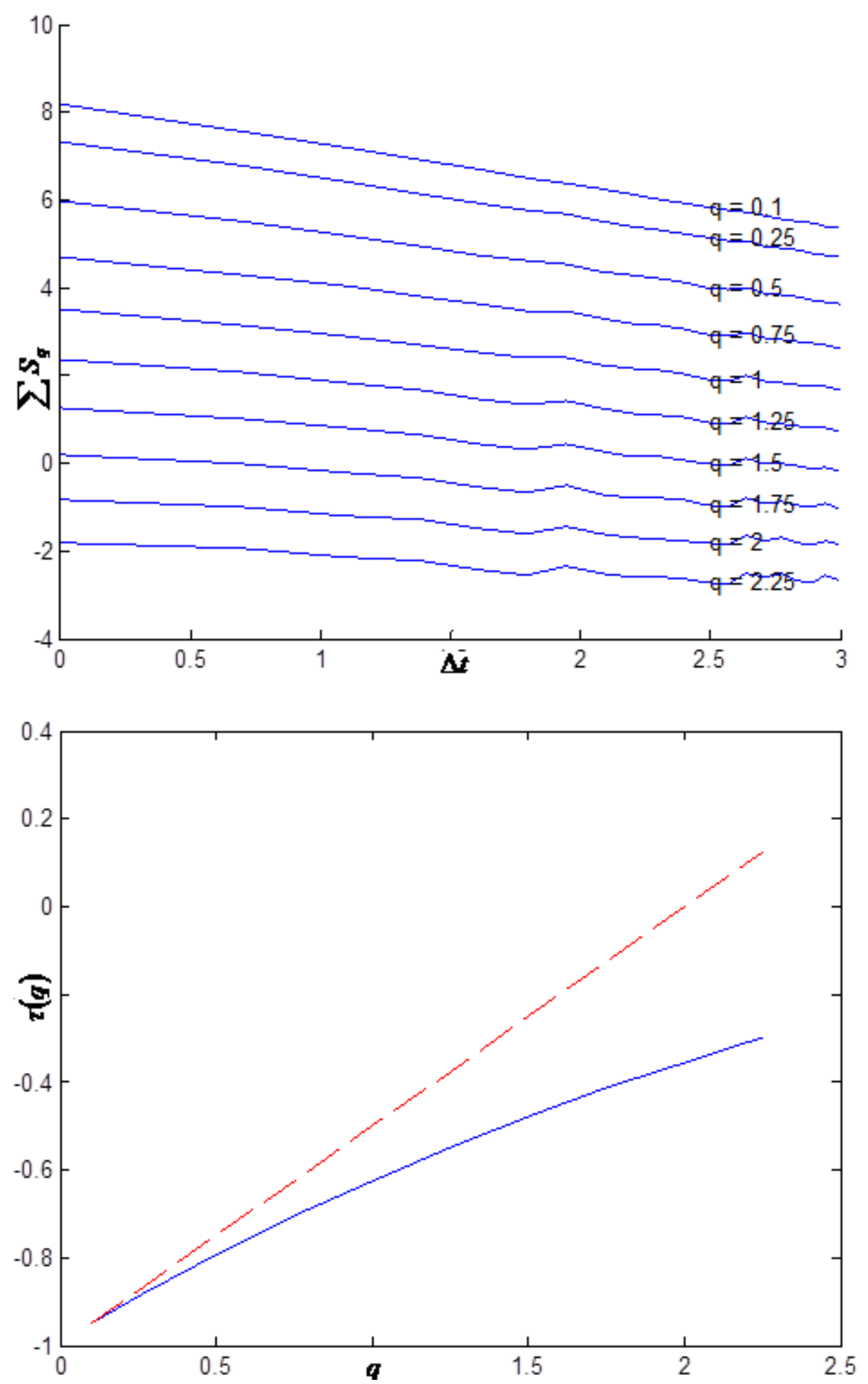

Figure 5. The Partition Function and Scaling Function for the DZD/EUR exchange rate 

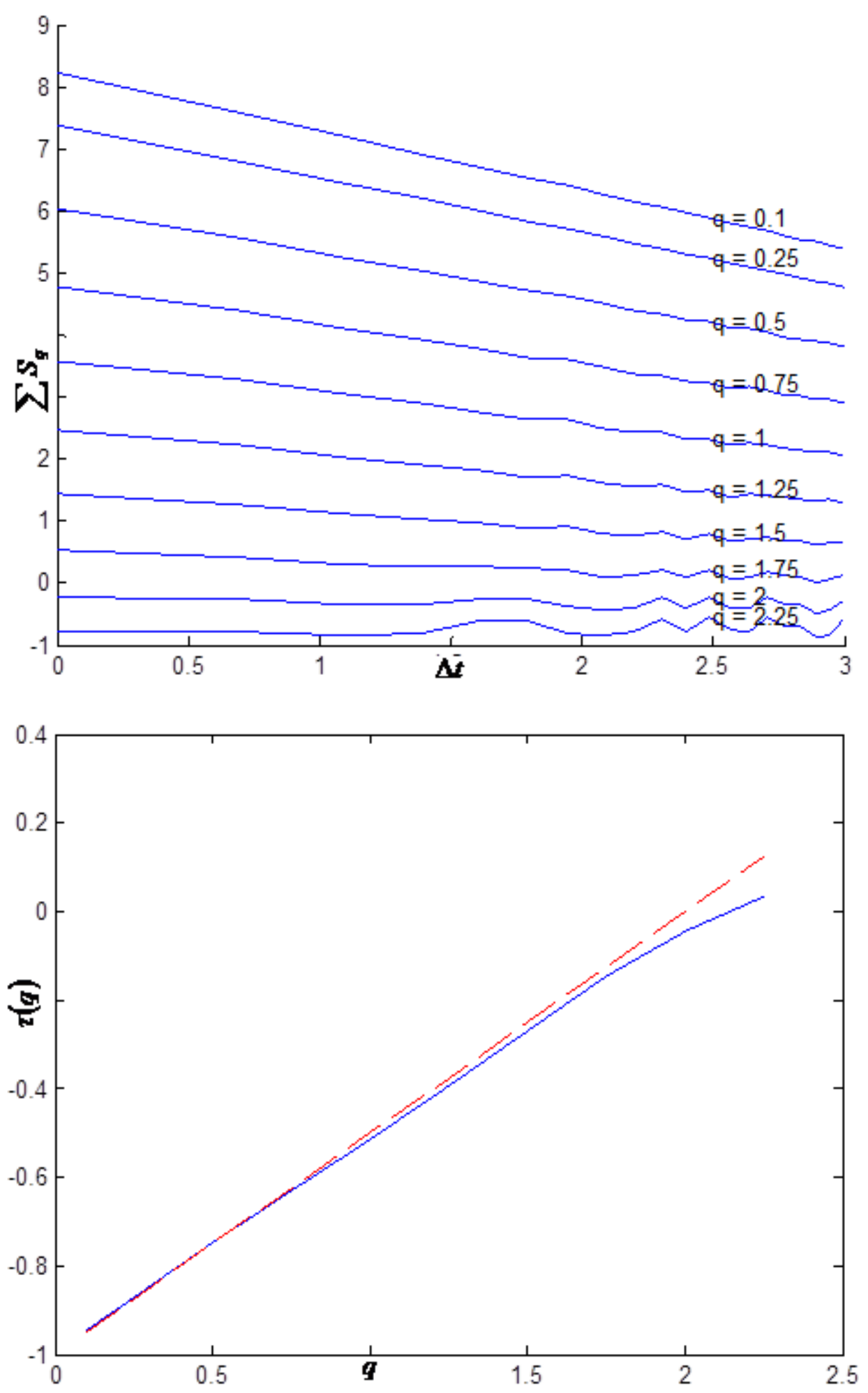

Figure 6. The Partition Function and Scaling Function for the EGP/EUR exchange rate 

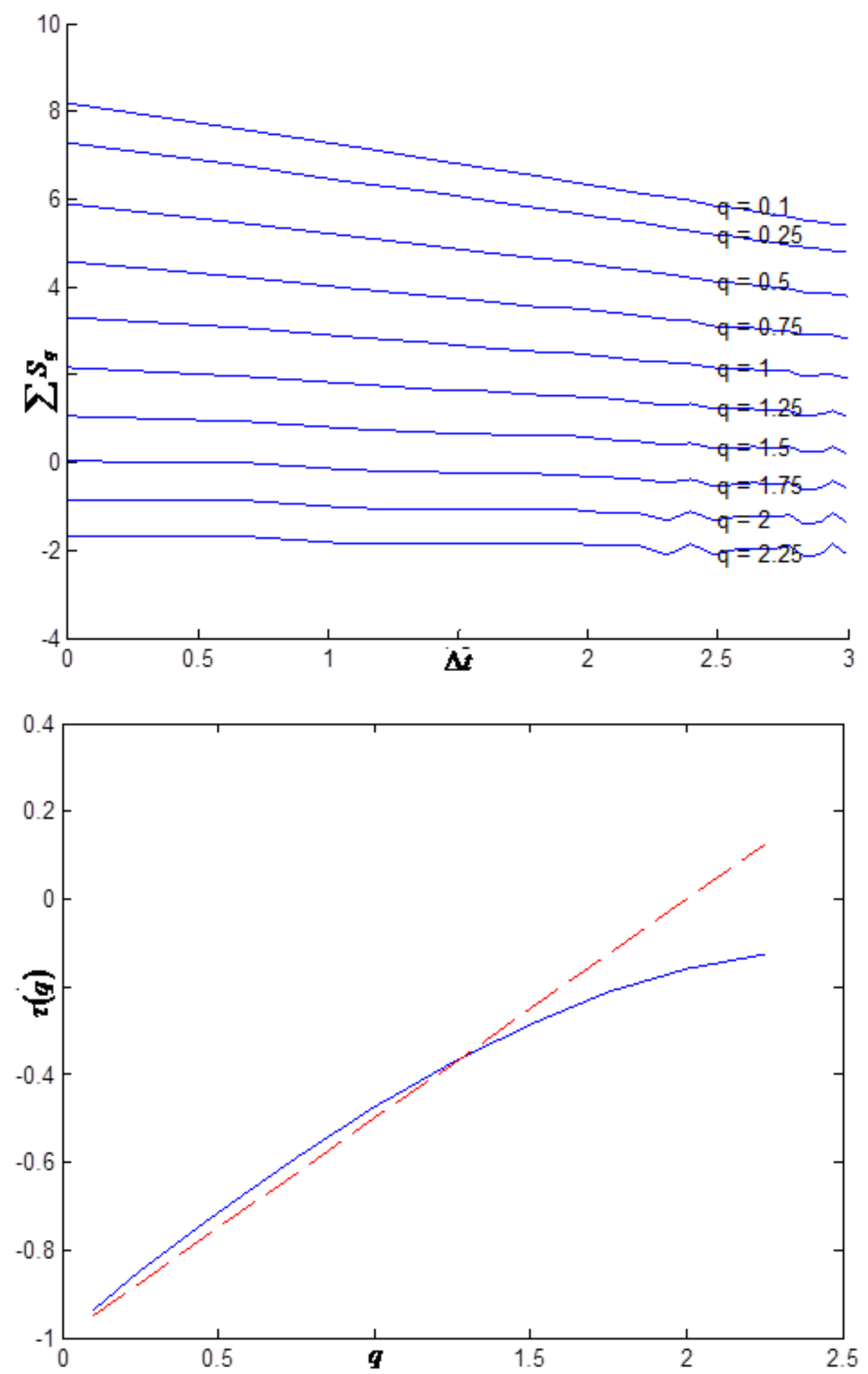

Figure 7. The Partition Function and Scaling Function for the ETB/EUR exchange rate 

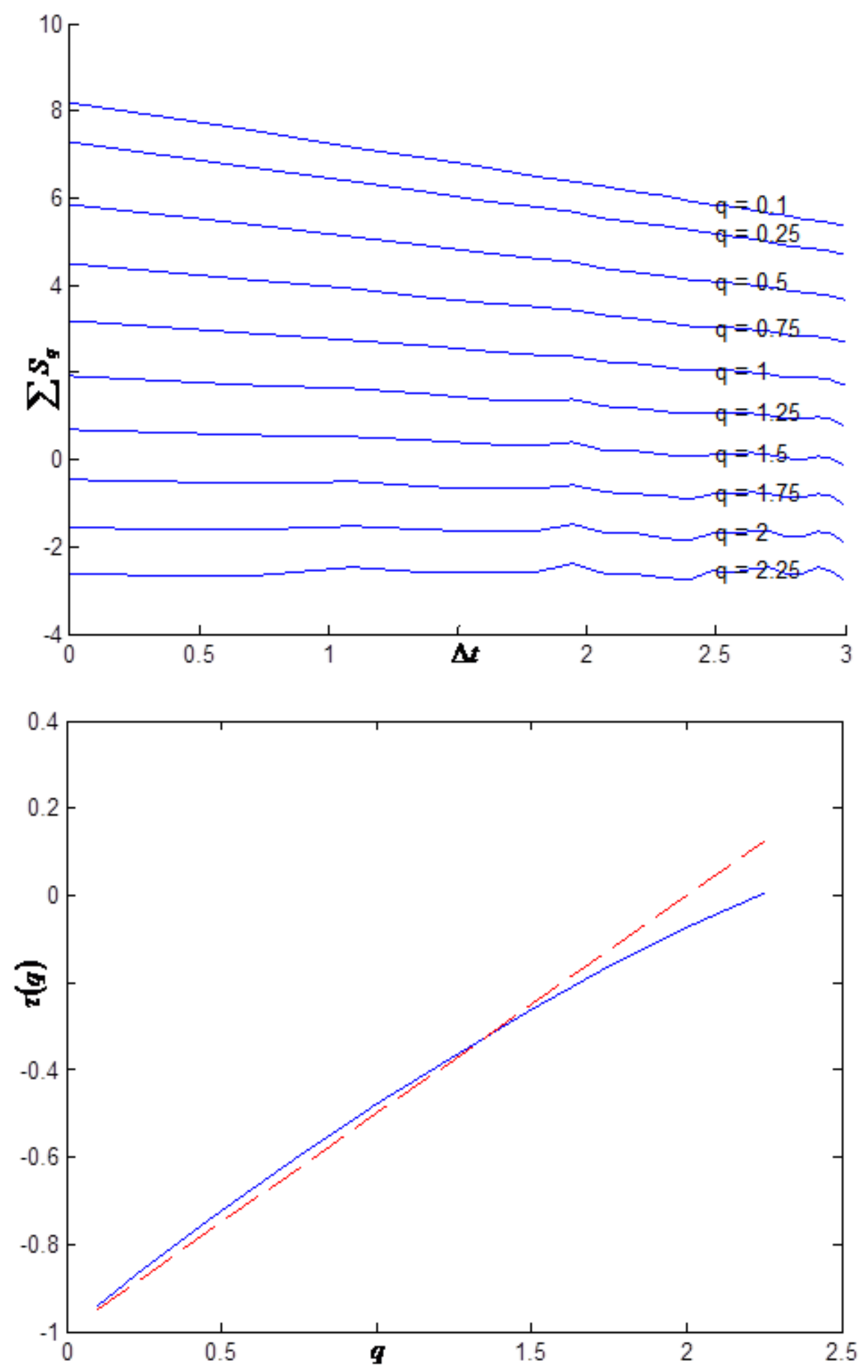

Figure 8. The Partition Function and Scaling Function for the ILS/EUR exchange rate 

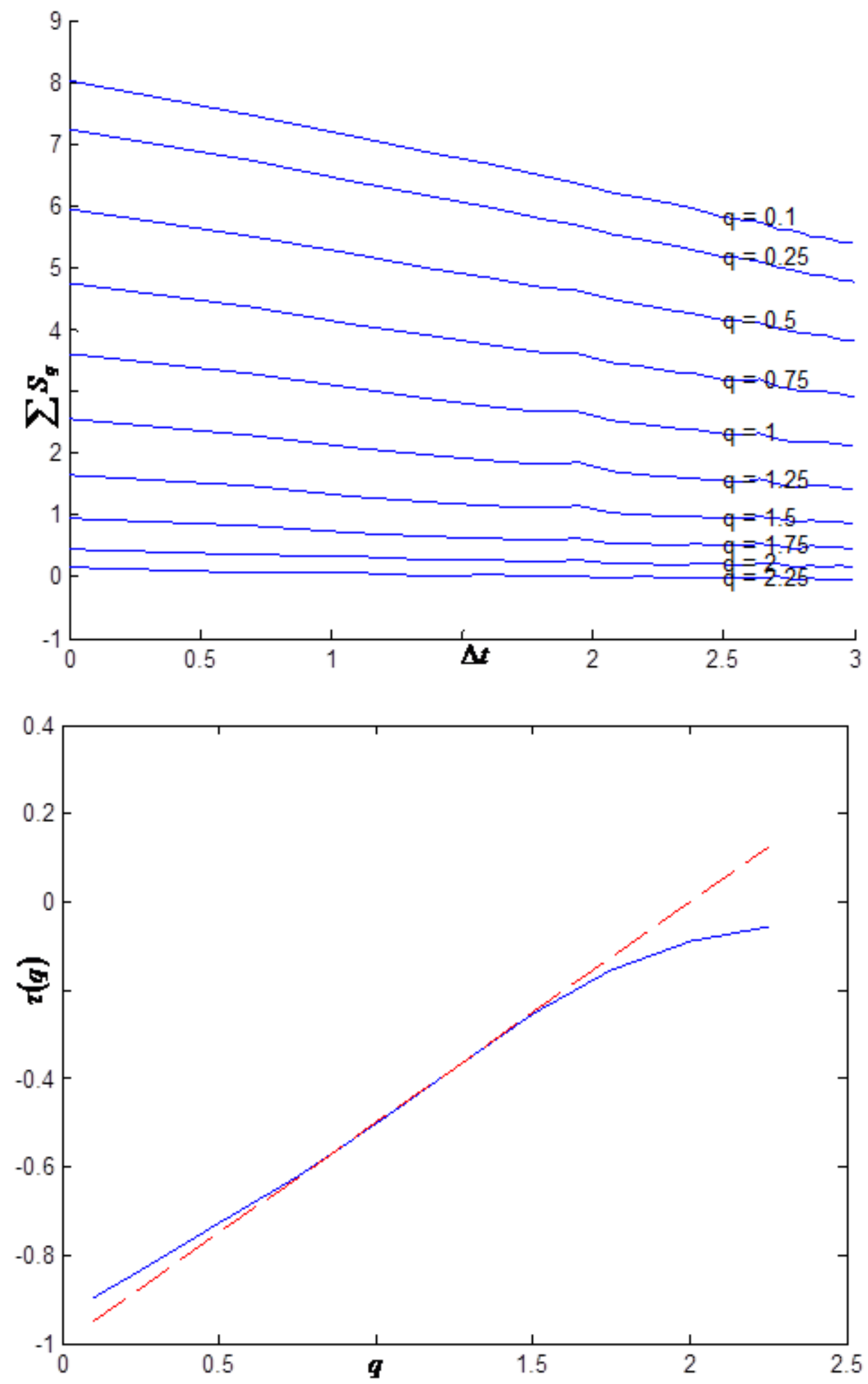

Figure 9. The Partition Function and Scaling Function for the IQD/EUR exchange rate 

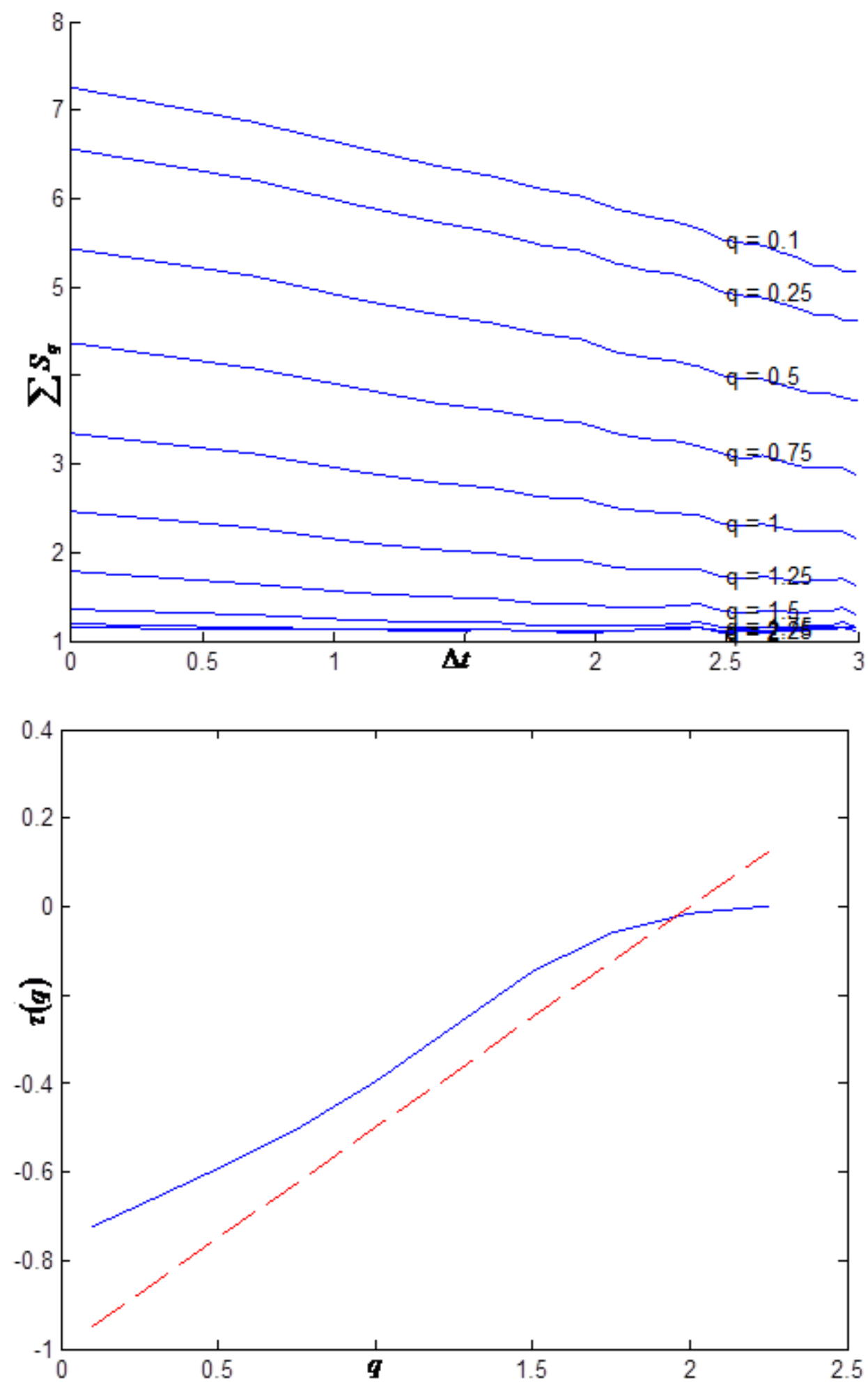

Figure 10. The Partition Function and Scaling Function for the IRR/EUR exchange rate 

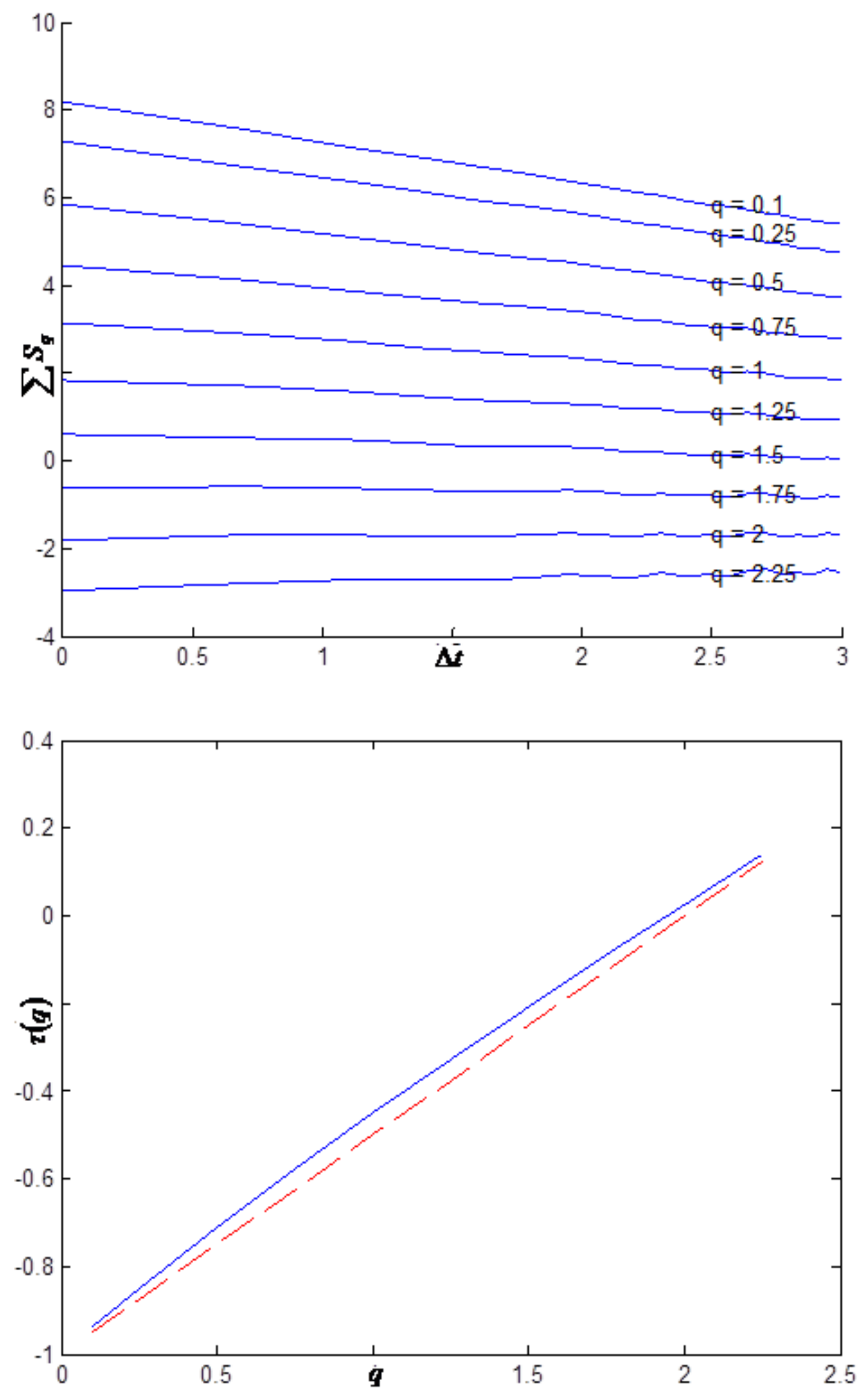

Figure 11. The Partition Function and Scaling Function for the JOD/EUR exchange rate 

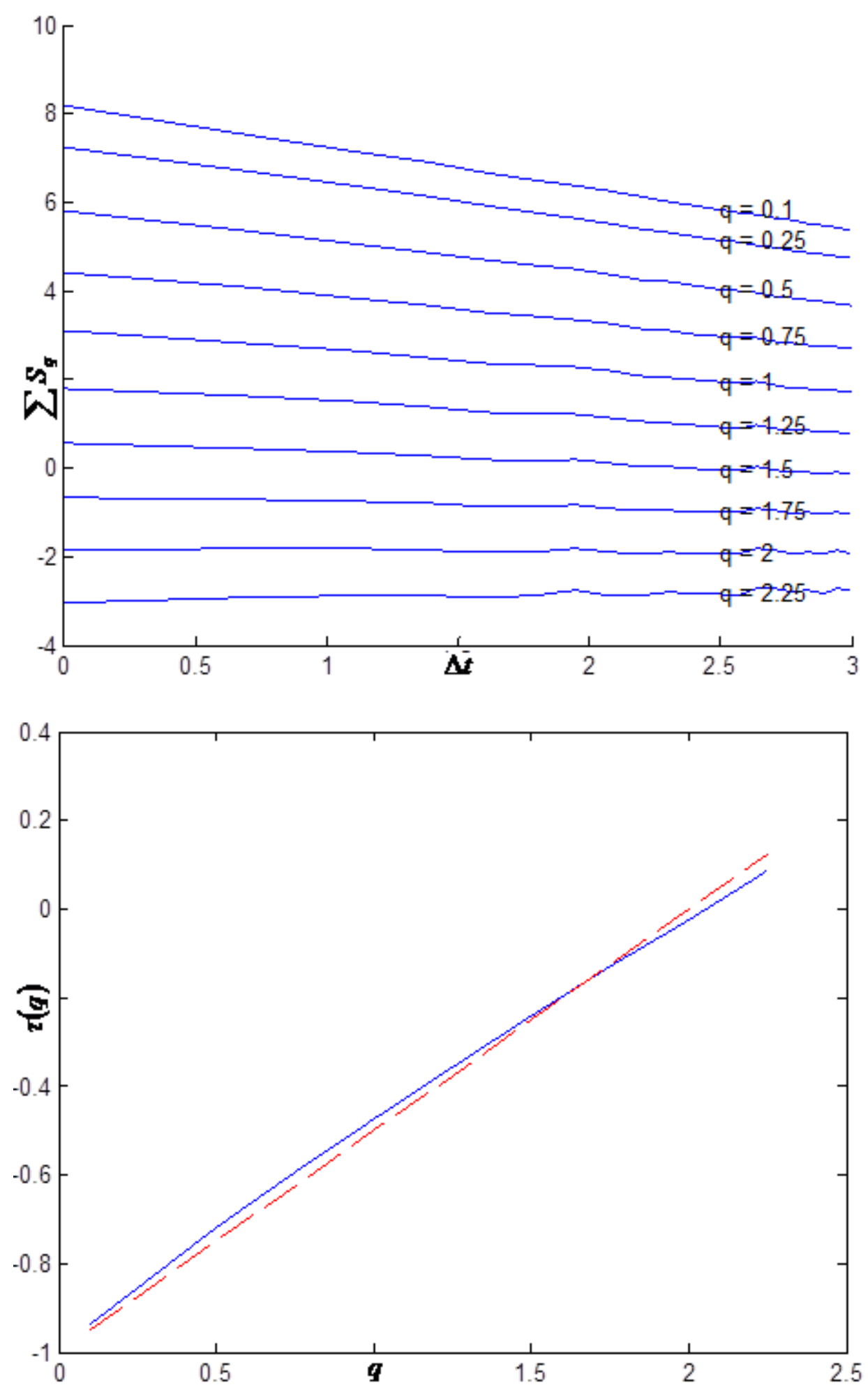

Figure 12. The Partition Function and Scaling Function for the KWD/EUR exchange rate 

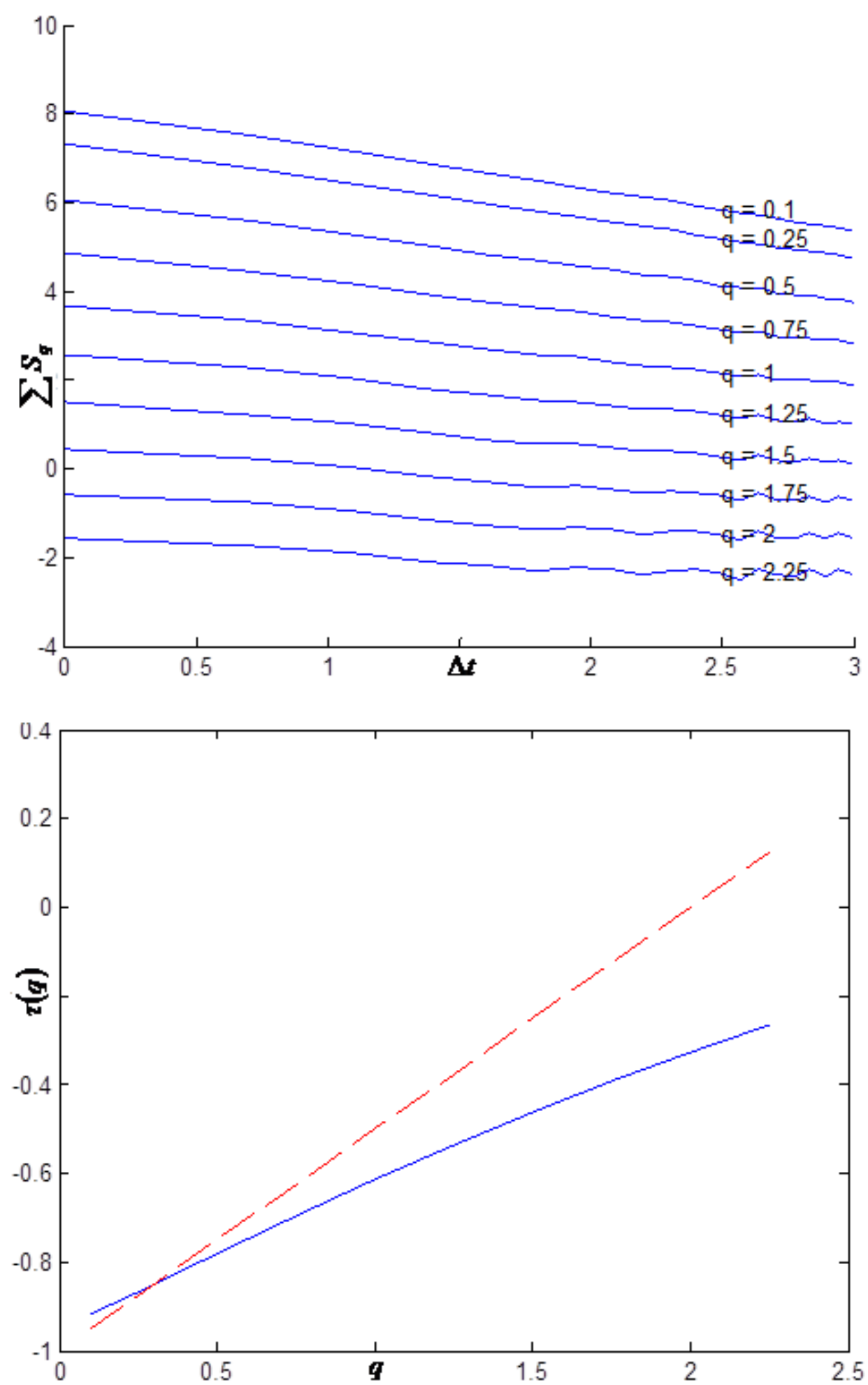

Figure 13. The Partition Function and Scaling Function for the LBP/EUR exchange rate 

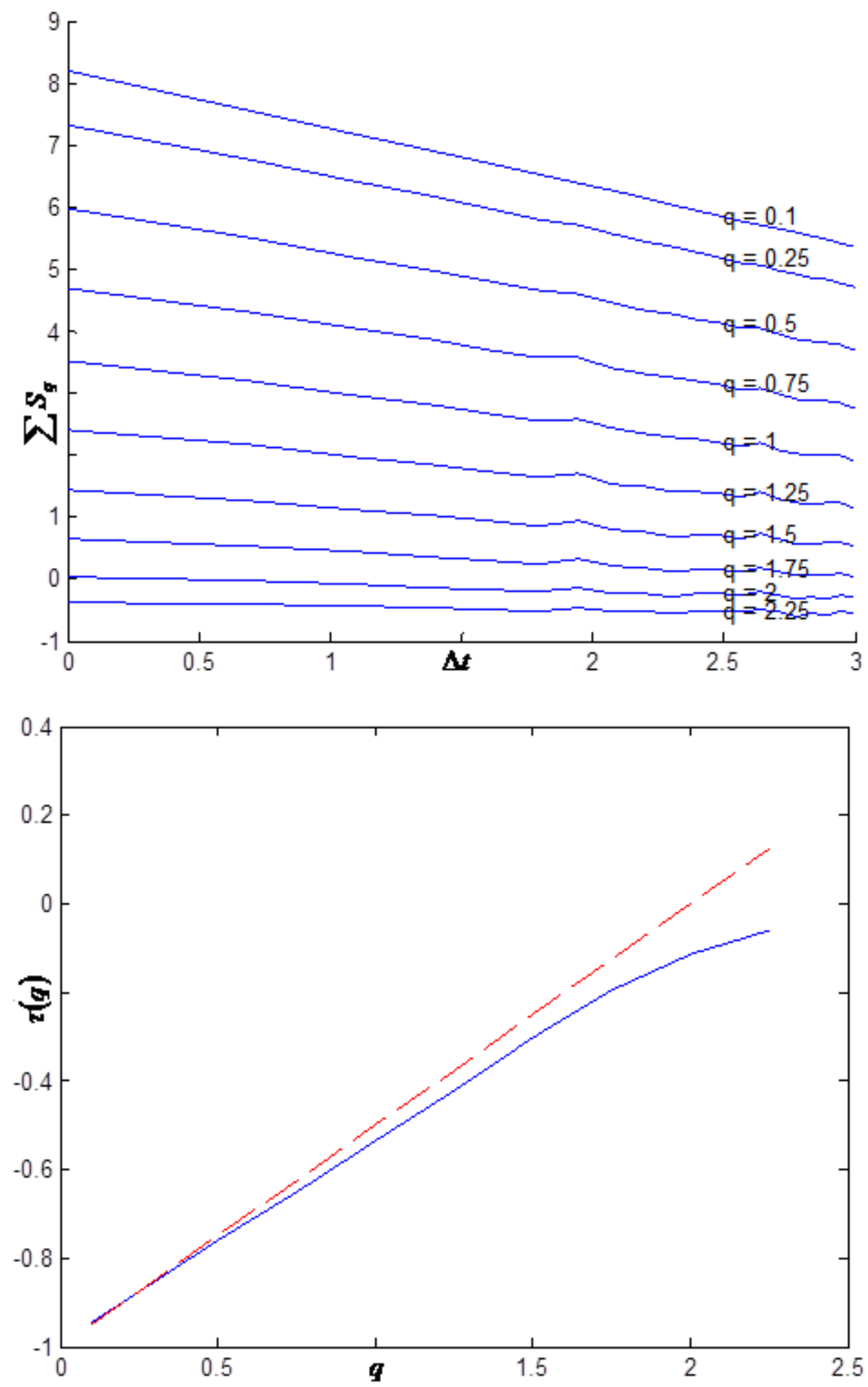

Figure 14. The Partition Function and Scaling Function for the LYD/EUR exchange rate 

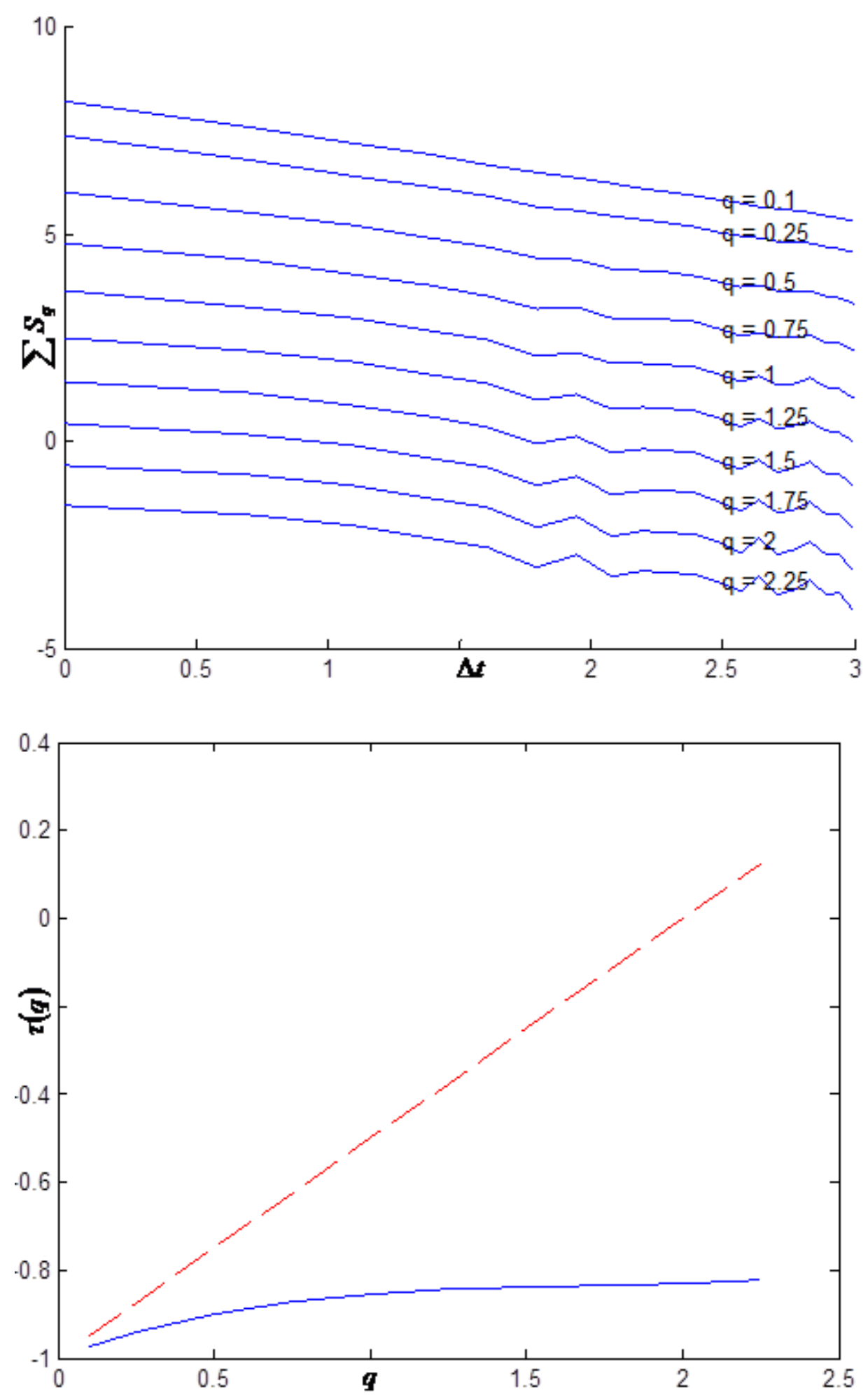

Figure 15. The Partition Function and Scaling Function for the MAD/EUR exchange rate 

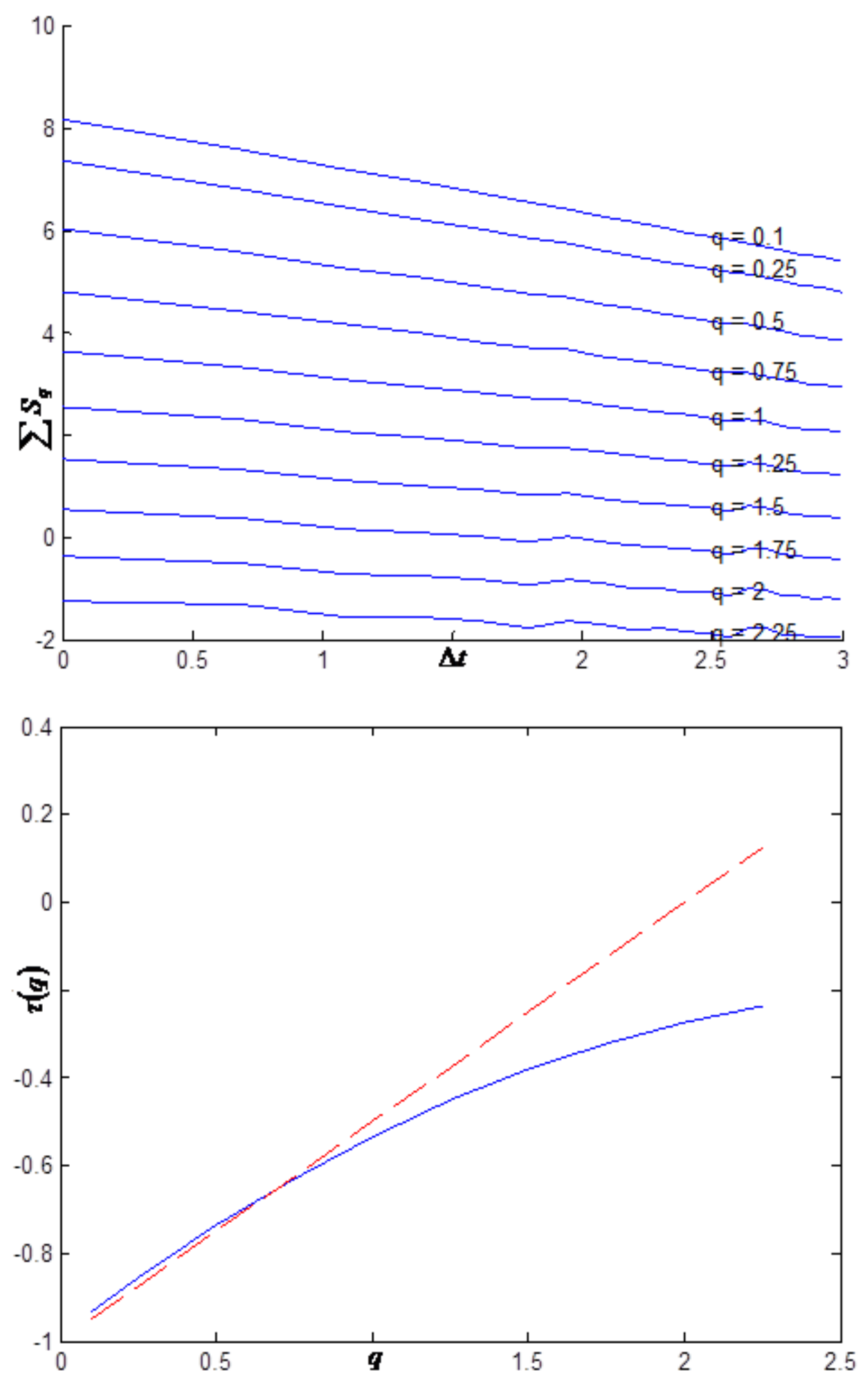

Figure 16. The Partition Function and Scaling Function for the MRO/EUR exchange rate 

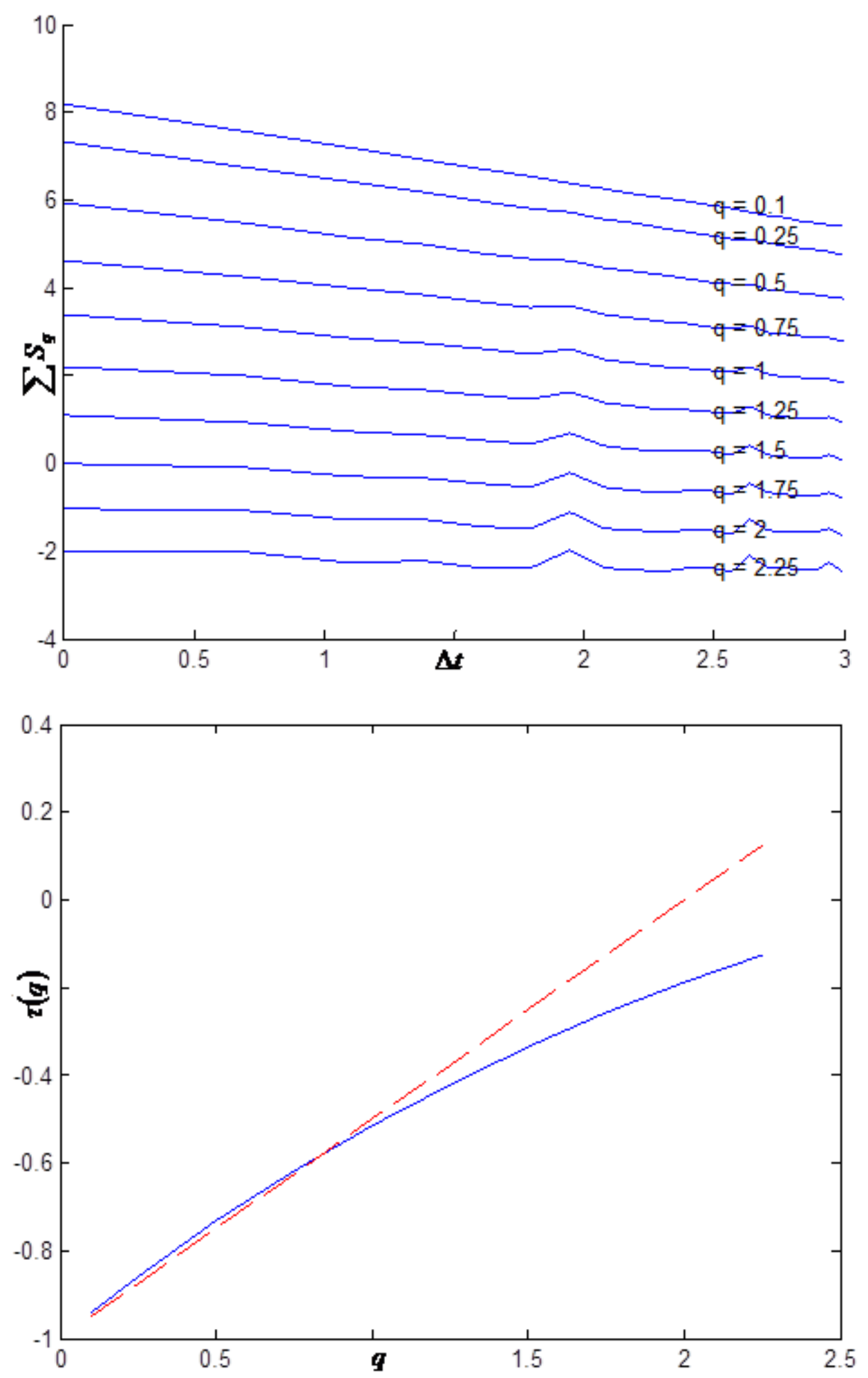

Figure 17. The Partition Function and Scaling Function for the QAR/EUR exchange rate 

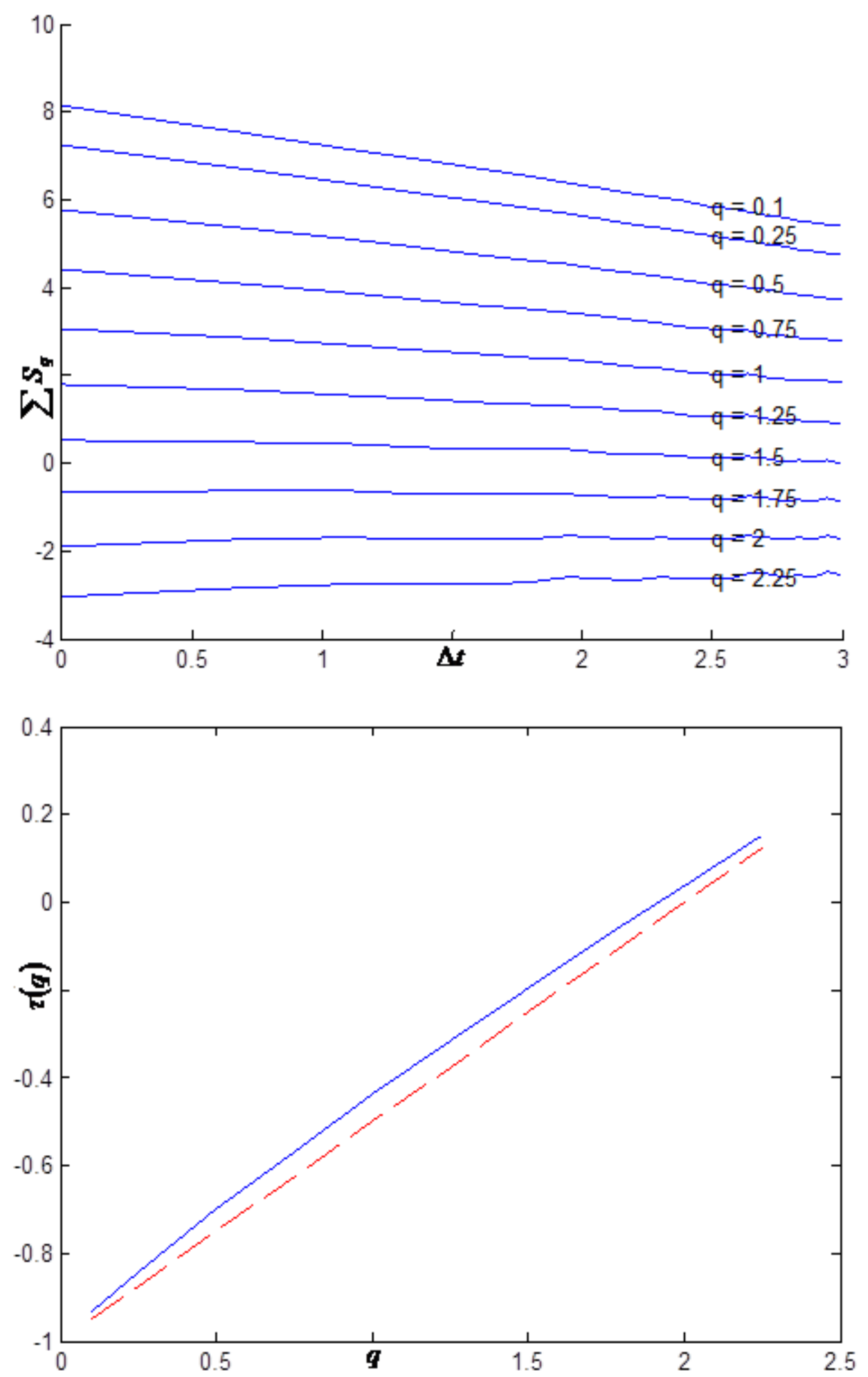

Figure 18. The Partition Function and Scaling Function for the SAR/EUR exchange rate 

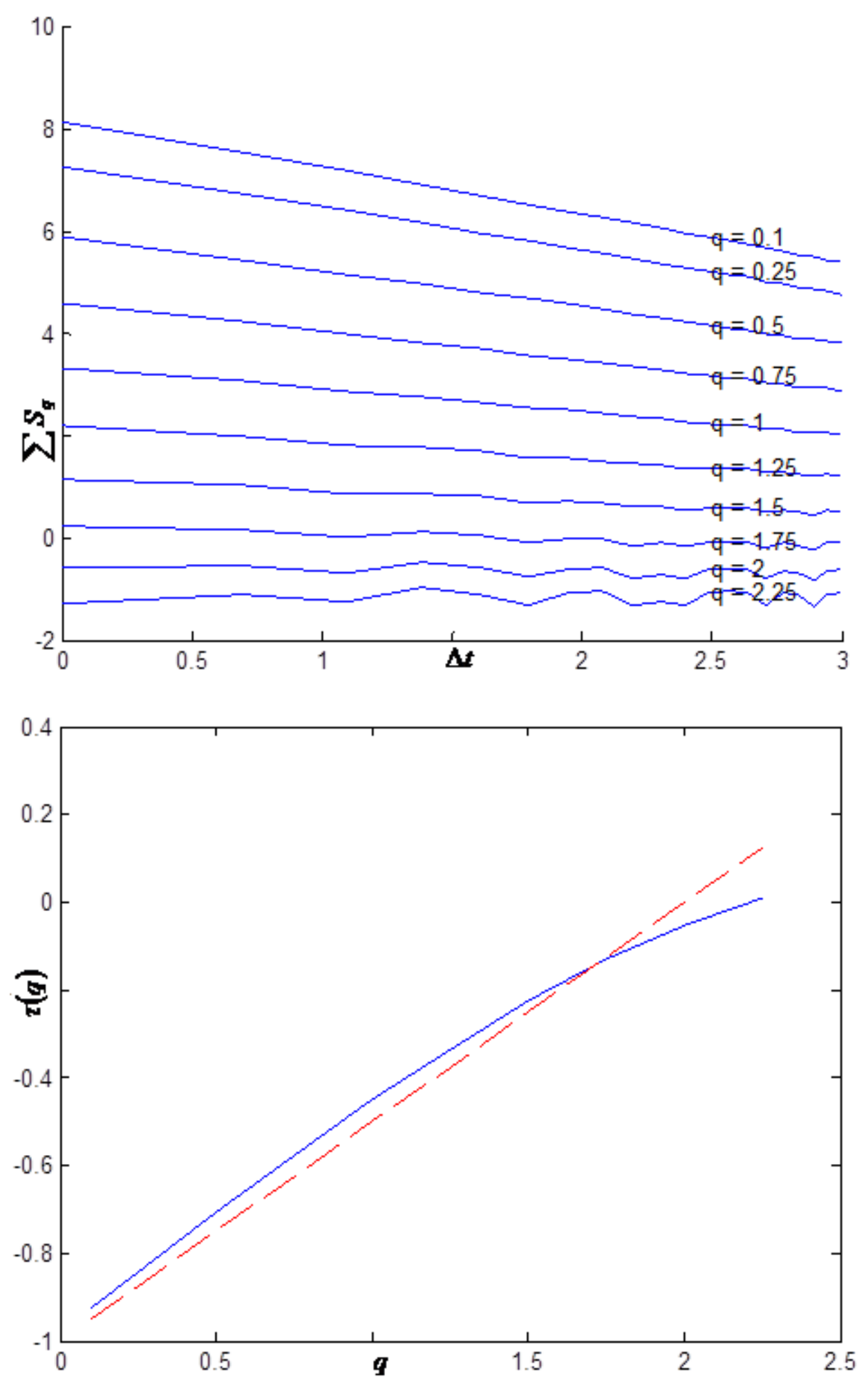

Figure 19. The Partition Function and Scaling Function for the SDD/EUR exchange rate 

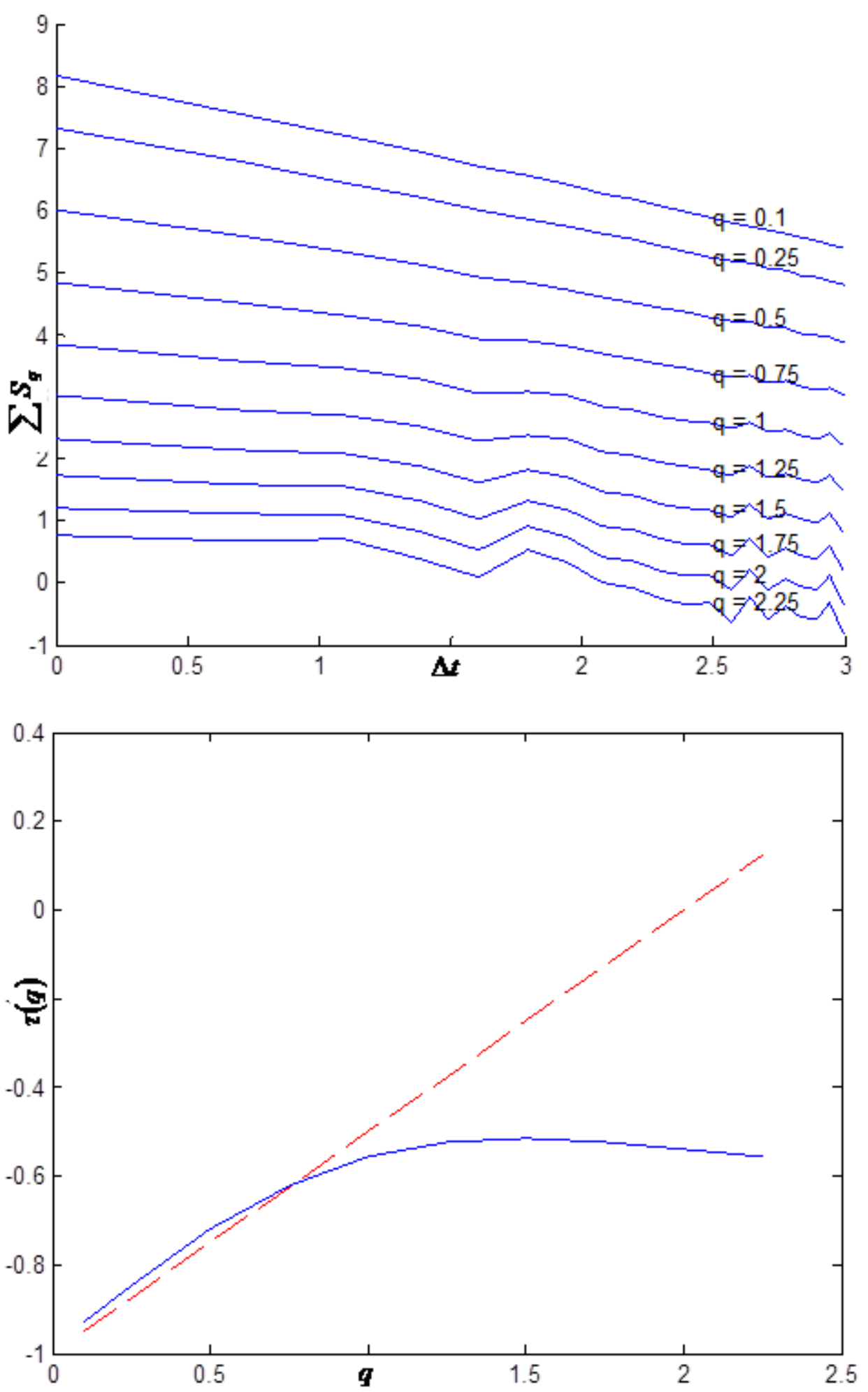

Figure 20. The Partition Function and Scaling Function for the SYP/EUR exchange rate 

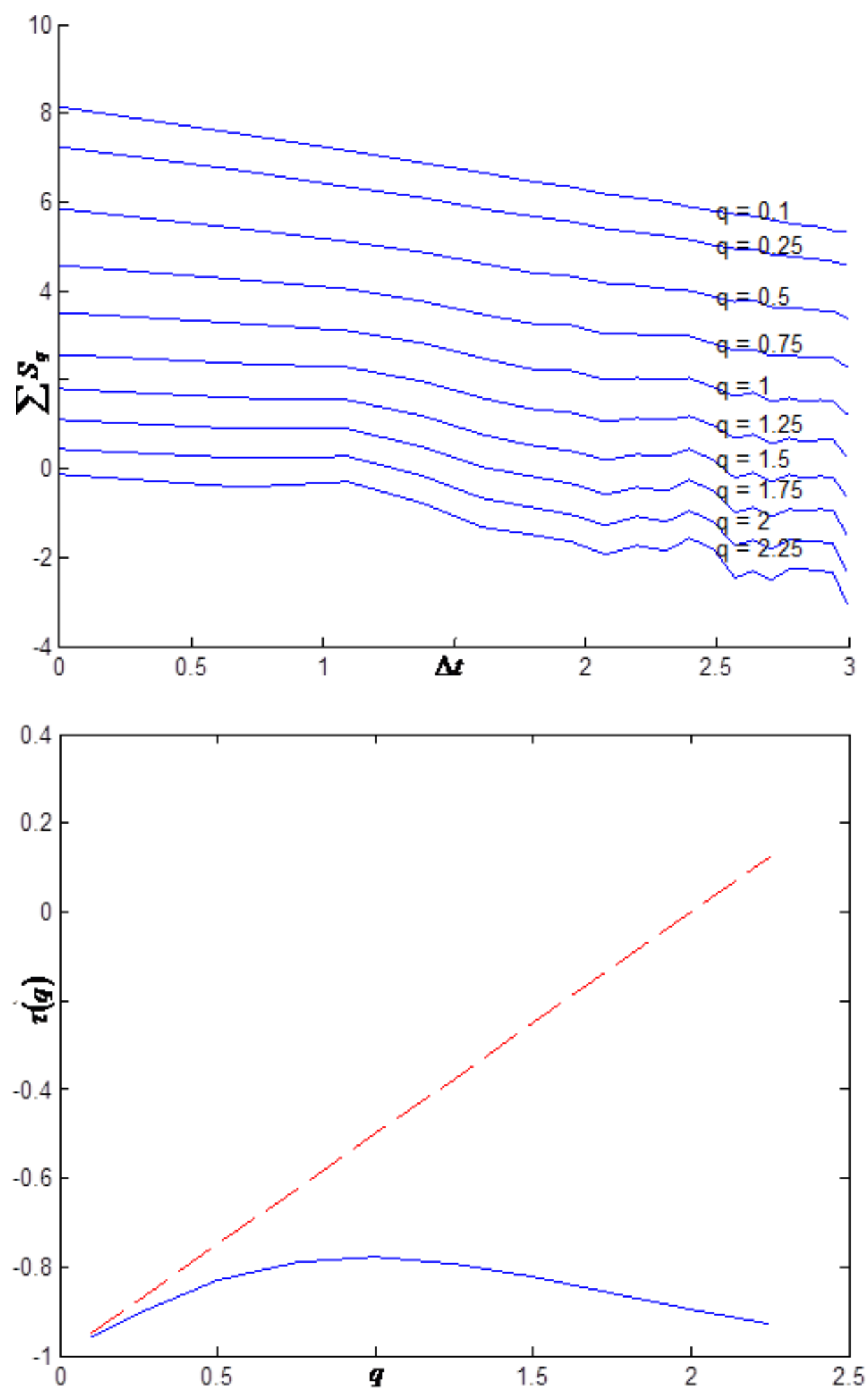

Figure 21. The Partition Function and Scaling Function for the TND/EUR exchange rate

The graphical representation of the partition function in Figure 2, shows the linear relationship between the logarithm of the sum of $S_{\sigma}$ and the logarithm of $\Delta t$. As well for the 20 sets of rates of exchange and for different values of $\mathrm{q}(0.1 \leq q \leq 2.25)$. We calculate the partition function. We see, almost the same result for all the series of exchange rates; all curves, for small values of $q$, show straight lines which implies the multifractality time series. Whereas for high values of $q(q>1.25)$, the curves become non-linear which brings us to estimate the scaling function 
of the exchange rate $\tau(q)$ from the partition function. The concavity observed of this function reveals the existence of relations of scale in the moments of the exchange rate. That is to say that there exists the same characteristic between the expectation (mean or the first moment), the variance, the moment of order 3...it is an uni-fractal series when there is only a single relationship of scale and a multifractal series when there are several. However, the observation of the graphs of the scaling function for the 20 series of exchange rates shows a broad diversification between countries MENA.

\subsection{Estimation of the Hurst Exponent}

For the estimation of the Hurst exponent, we use two methods, namely: The GQV method (Generalized Quadratic Variations), mentioned above, which allows estimating the Hurst exponent as a function of time, C-to-D H(t). The method IRS (increment ratio statistic), introduced by Bardet et al. 2008, which allows estimating the Hurst exponent Global. These two estimators are available in the Toolbox Fraclab (the Software Matlab) intended for the treatment of the signal fractal and multifractal. The results obtained are outlined in the table below. In effect, the visual randing of these graphs indicates a diversity between the different functions $\mathrm{H}(\mathrm{t})$ and exhibitors of global Hurst $\hat{H}_{\text {IRS }}$, estimated for all countries MENA. We also find that $\mathrm{H}(\mathrm{t})$ is not stable for all series of the rate of exchange. The pace of this function still resembles a random process ranging irregularly between 0 and 1 . This irregularity explains the concept of FMH which is significantly related to the multifractality rates of exchange. We note, in addition, that $\mathrm{H}$ is always different to 0.5 . Therefore the series follows an $\mathrm{mBm}$ which means the observations are correlated and each having kept the memory of all previous events.

In effect, the Hurst exponent provides a measure of the intensity of the long-range dependence (or so-called long memory). When $\mathrm{H}=0.5$, there is no correlation and the signal is an uncorrelated signal. It is a Brownian movement which explains the efficiency of the market. If $\mathrm{H}<0.5$, the signal is anticorrelated (or so-called anti-persistent process), i.e. upward phases tend to be followed by downward phases and successive increments tend to be negatively correlated. The market overreacts, showing a lack of investor confidence. Whereas, if $\mathrm{H}>0.5$, there are positive correlations in the signal.

Each observation is the memory of the events that preceded it. Therefore the process presents a form of long memory i.e. that the evolution of the series tends to follow trends. In this case, the market reacts too weakly reflecting an excess of confidence. The following figures provide visual comparisons between the different exchange rates of the MENA countries against the euro.

Table 2. Results of the estimation of $\mathrm{H}$ for UAE

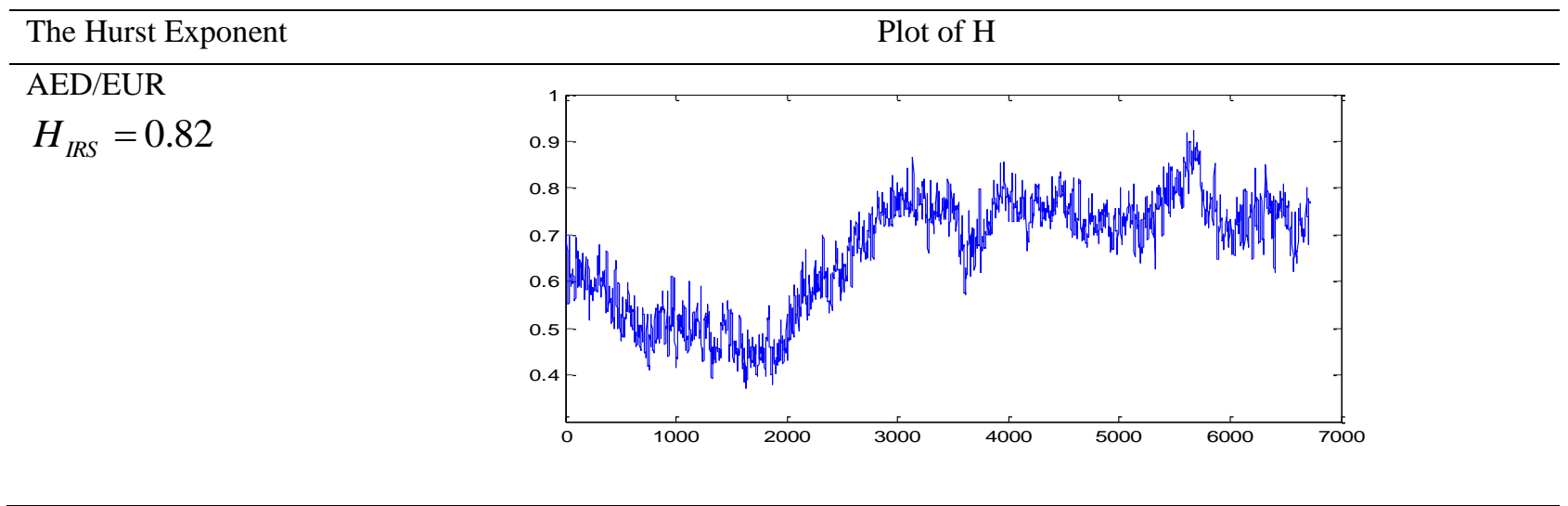


Table 3. Results of the estimation of $\mathrm{H}$ for Bahrain

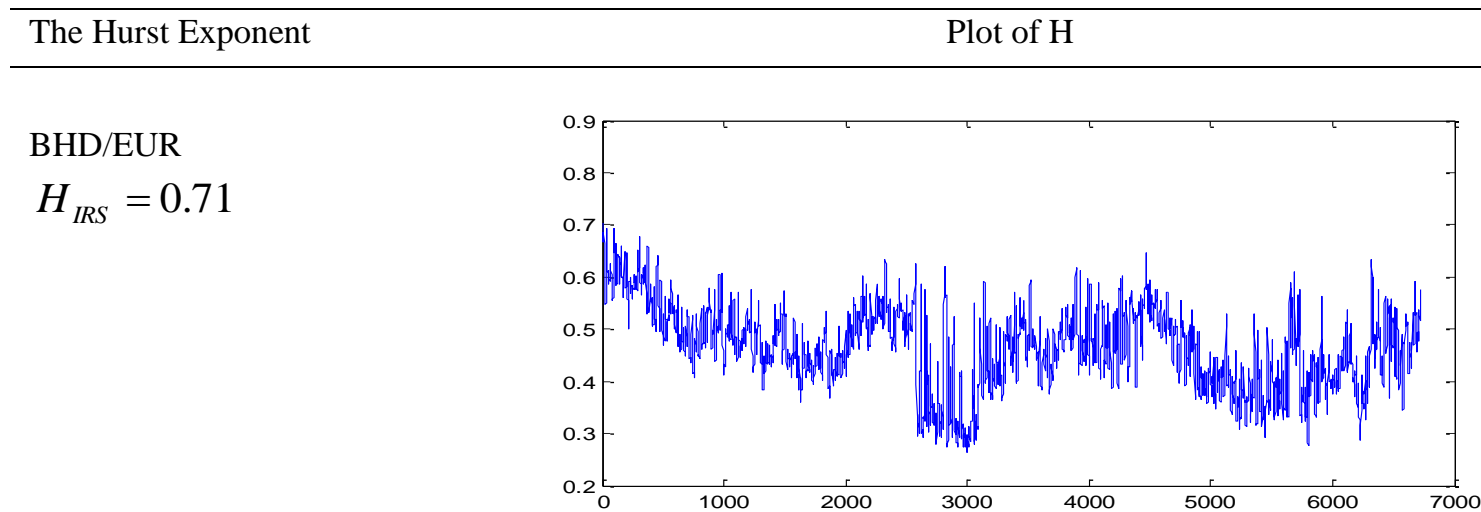

Table 4. Results of the estimation of $\mathrm{H}$ for Djibouti

The Hurst Exponent

Table 5. Results of the estimation of $\mathrm{H}$ for Algeria

The Hurst Exponent

Plot of $\mathrm{H}$

$$
\begin{aligned}
& \text { DZD/EUR } \\
& H_{I R S}=0.68
\end{aligned}
$$

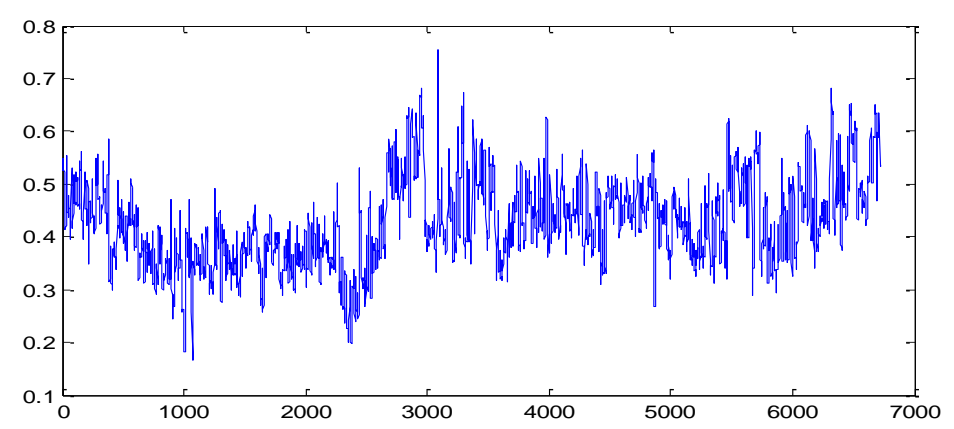


Table 6. Results of the estimation of $\mathrm{H}$ for Egypt

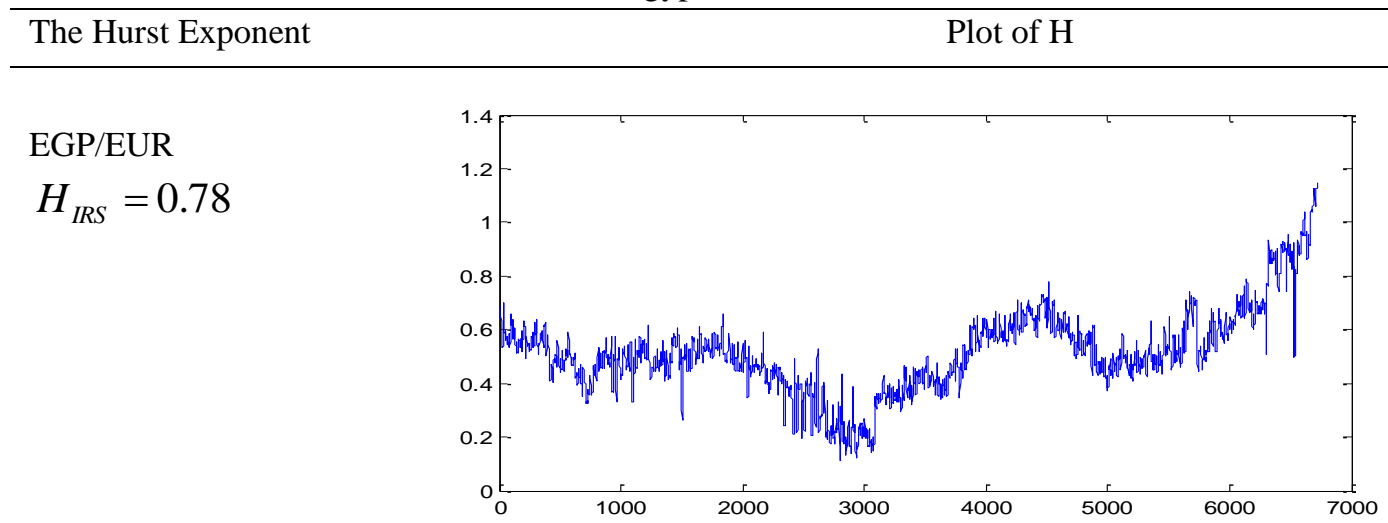

Table 7. Results of the estimation of $\mathrm{H}$ for Ethiopia

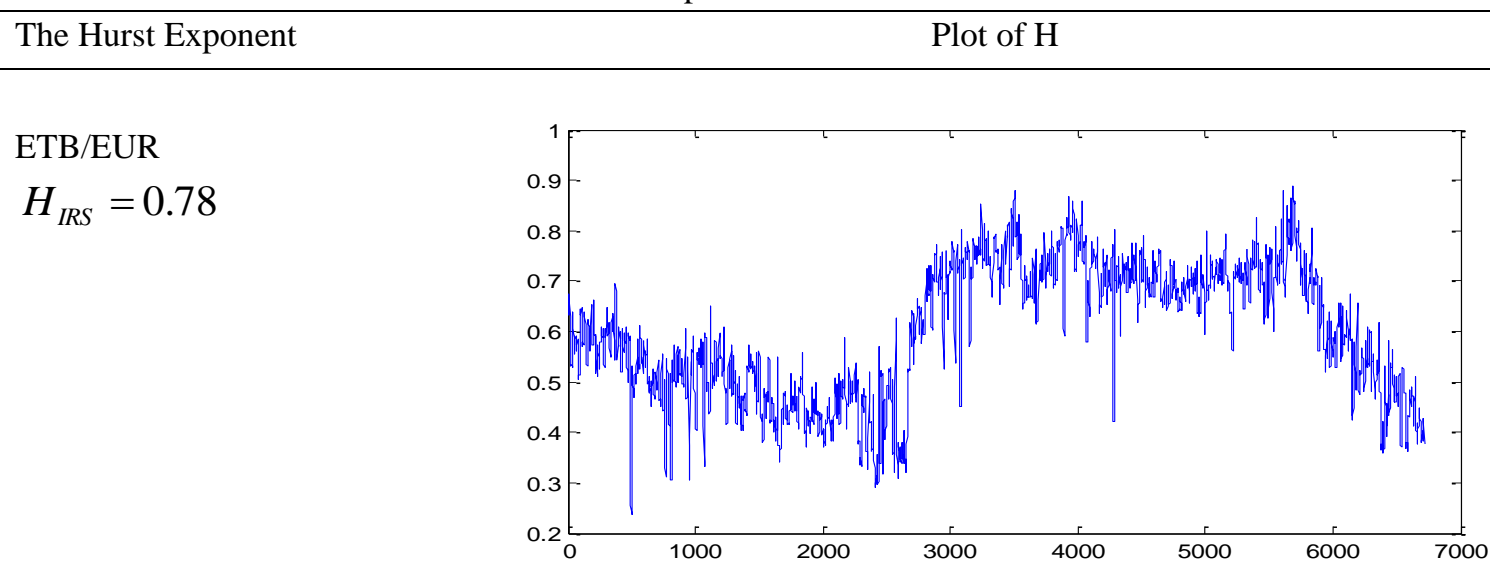

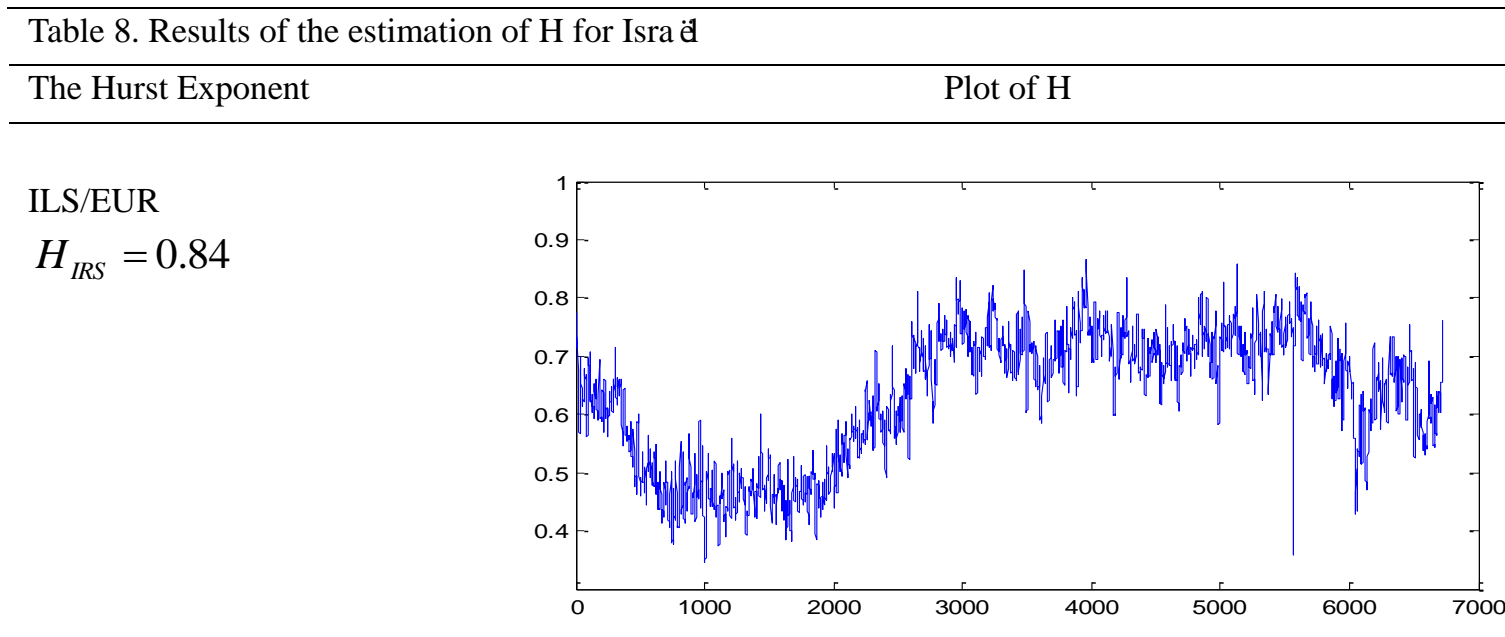


Table 9. Results of the estimation of $\mathrm{H}$ for Iraq

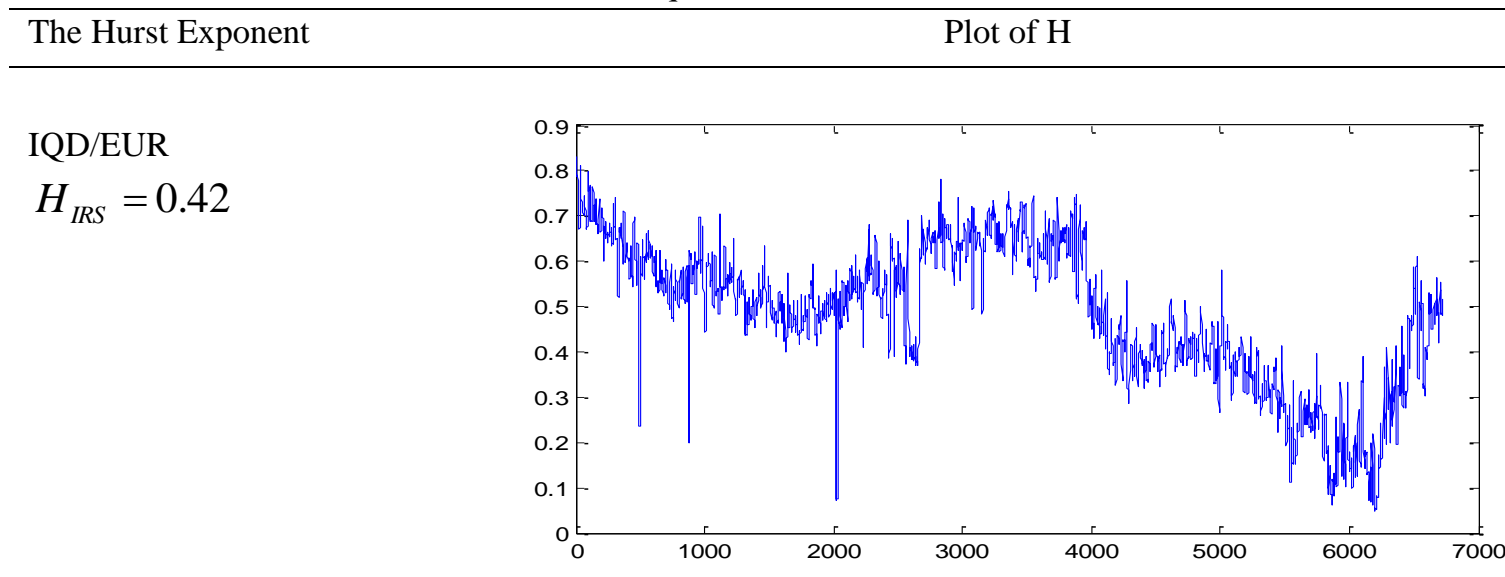

Table 10. Results of the estimation of $\mathrm{H}$ for Iran

IRR/EUR

$H_{\text {IRS }}=0.47$

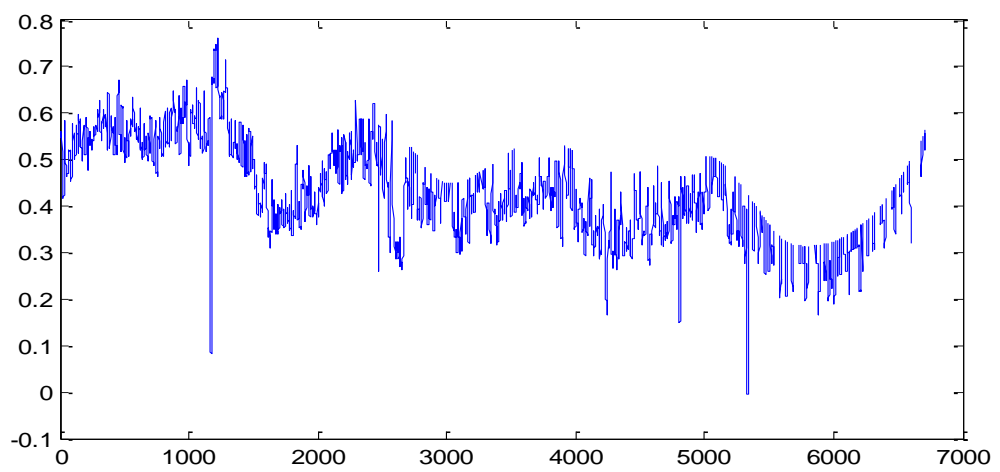

Table 11. Results of the estimation of $\mathrm{H}$ for Jordan

The Hurst Exponent

Plot of $\mathrm{H}$

JOD/EUR

$H_{\text {IRS }}=0.75$

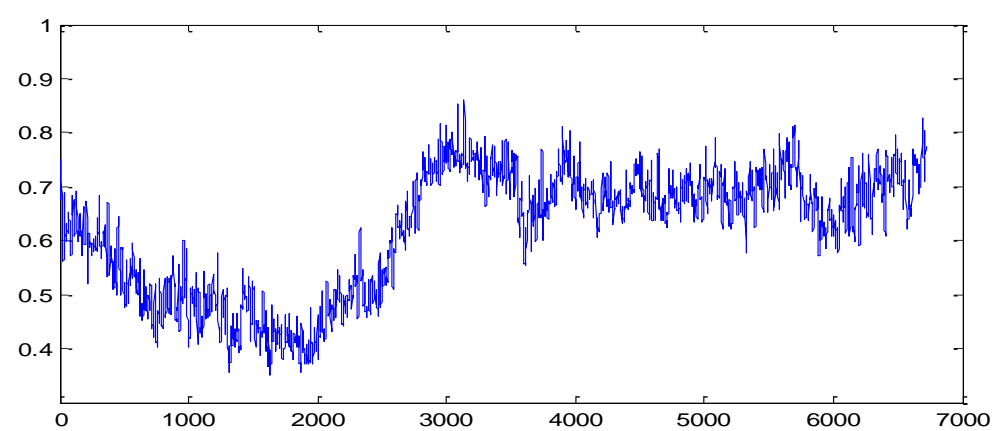


Table 12. Results of the estimation of $\mathrm{H}$ for Kuwait

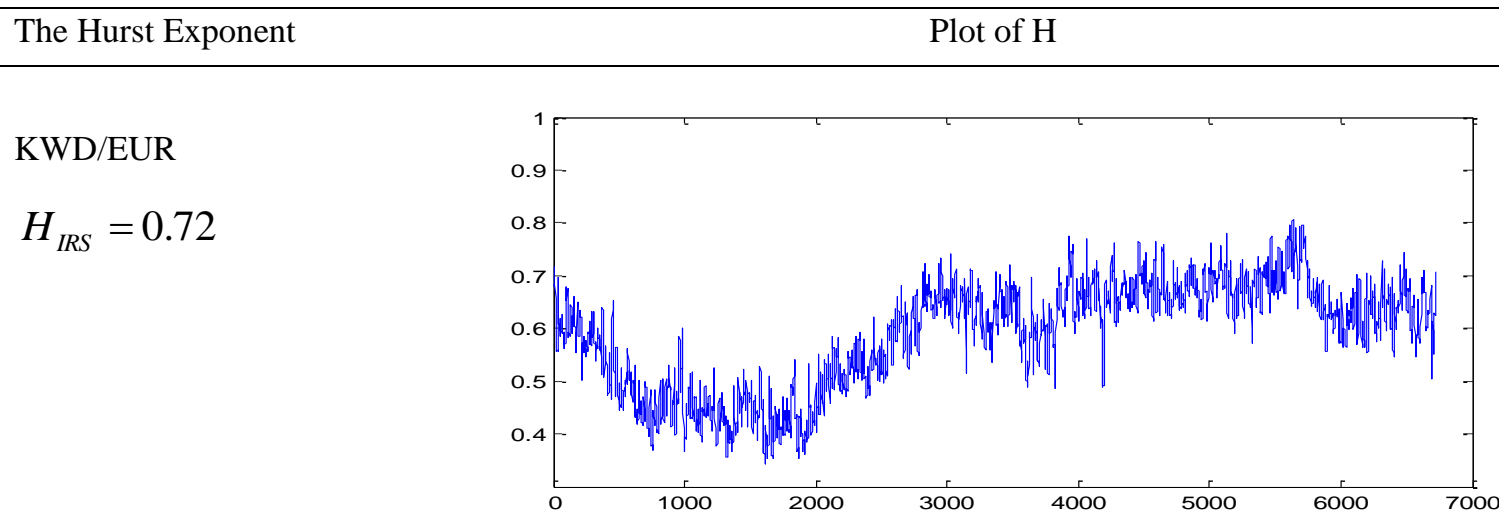

Table 13. Results of the estimation of $\mathrm{H}$ for Libanon

The Hurst Exponent $\quad$ Plot of $\mathrm{H}$

LBP/EUR

$H_{\text {IRS }}=0.33$

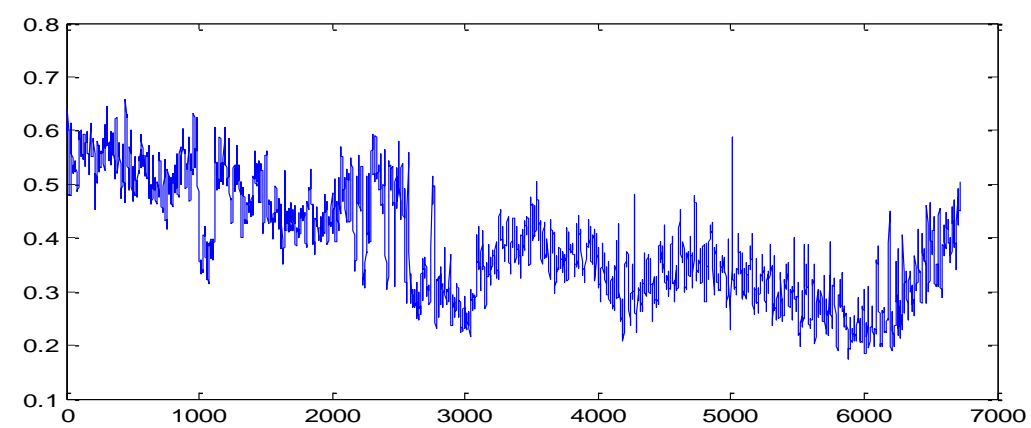

Table 14. Results of the estimation of H for Libya

The Hurst Exponent

Plot of $\mathrm{H}$

LYD/EUR

$H_{\text {IRS }}=0.64$

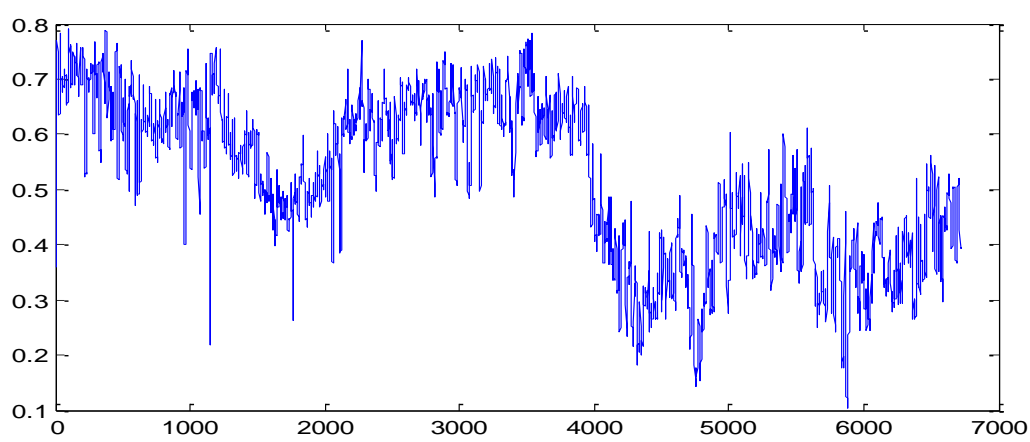


Table 15. Results of the estimation of $\mathrm{H}$ for Morocco

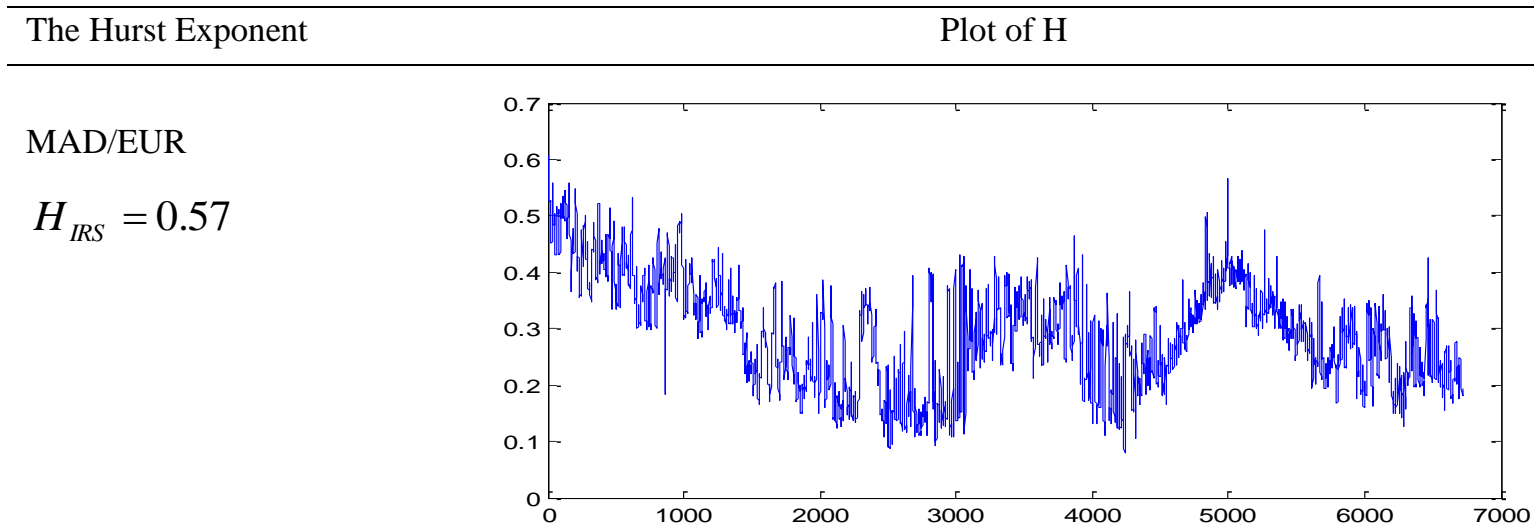

Table 16. Results of the estimation of $\mathrm{H}$ for Mauritania

The Hurst Exponent $\quad$ Plot of $\mathrm{H}$

MRO/EUR

$H_{\text {IRS }}=0.33$

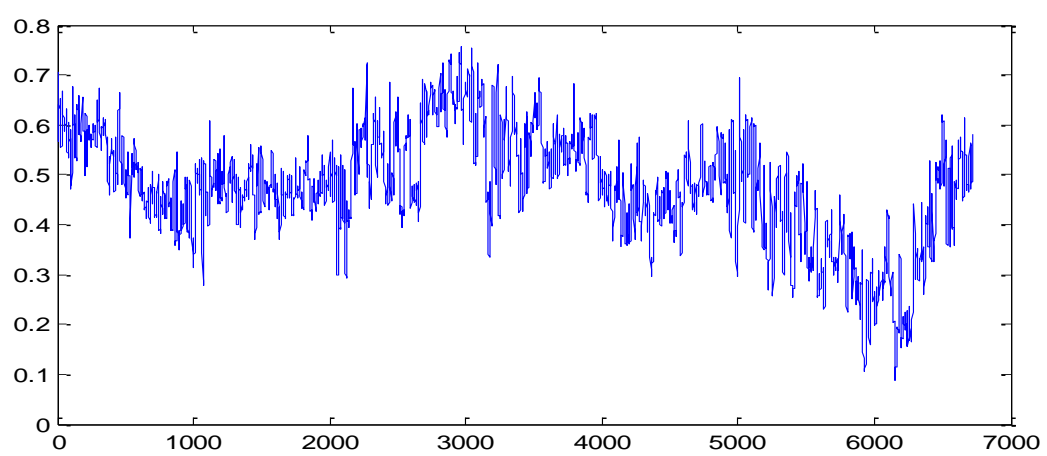

Table 17. Results of the estimation of $\mathrm{H}$ for Qatar

The Hurst Exponent

Plot of $\mathrm{H}$

QAR/EUR

$H_{I R S}=0.78$

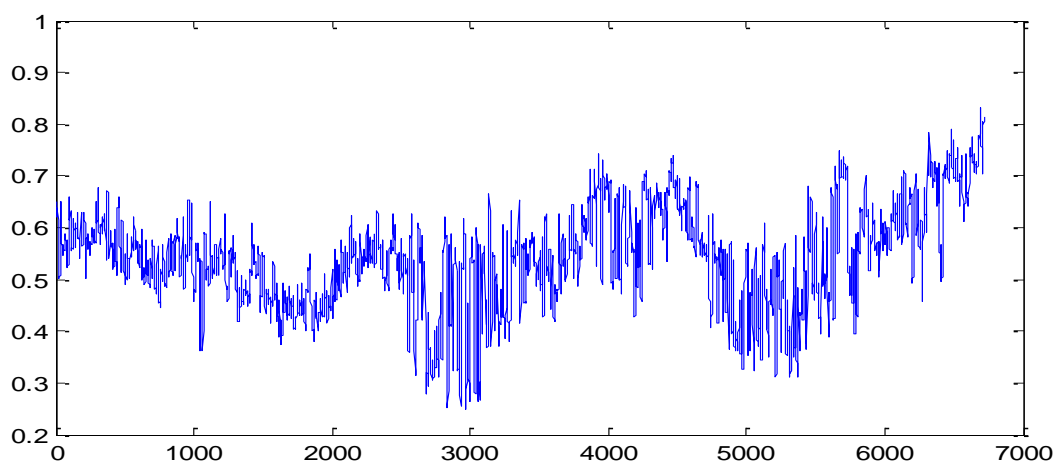


Table 18. Results of the estimation of $\mathrm{H}$ for Saudi Arabia

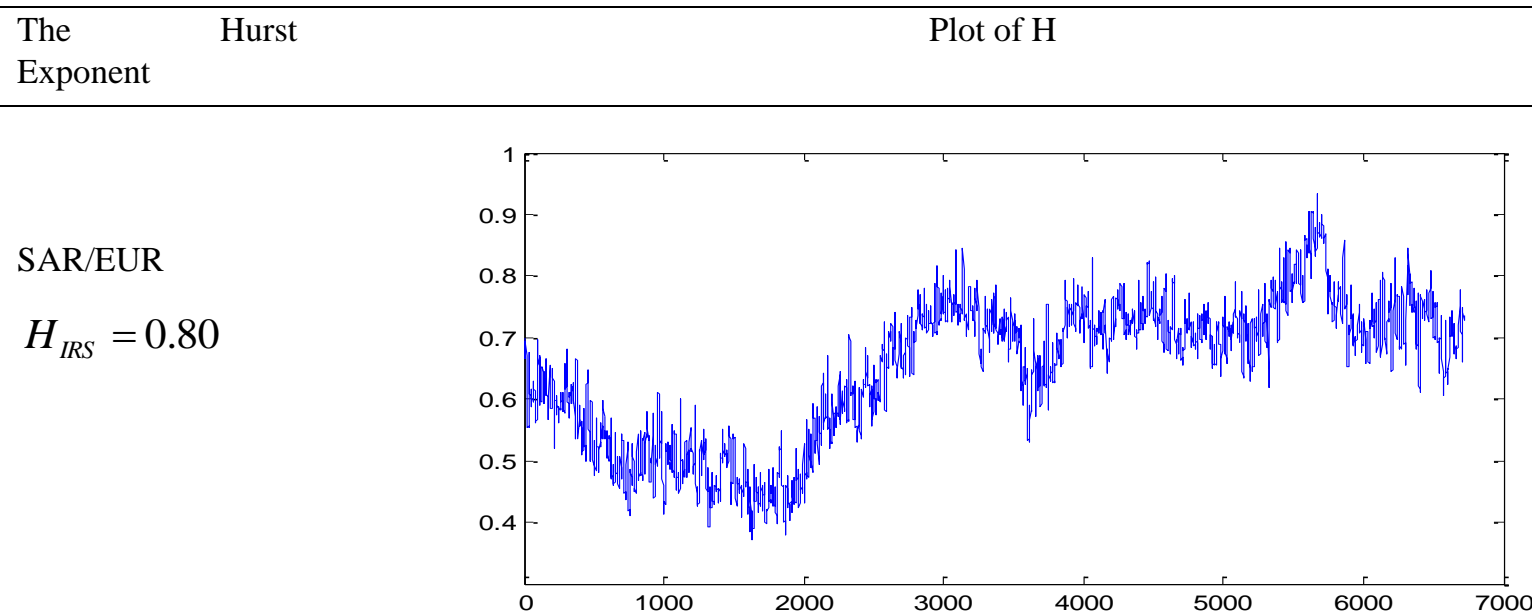

Table 19. Results of the estimation of $\mathrm{H}$ for Sudan

The Hurst Plot of $\mathrm{H}$

Exponent

SDD/EUR

$H_{\text {IRS }}=0.45$

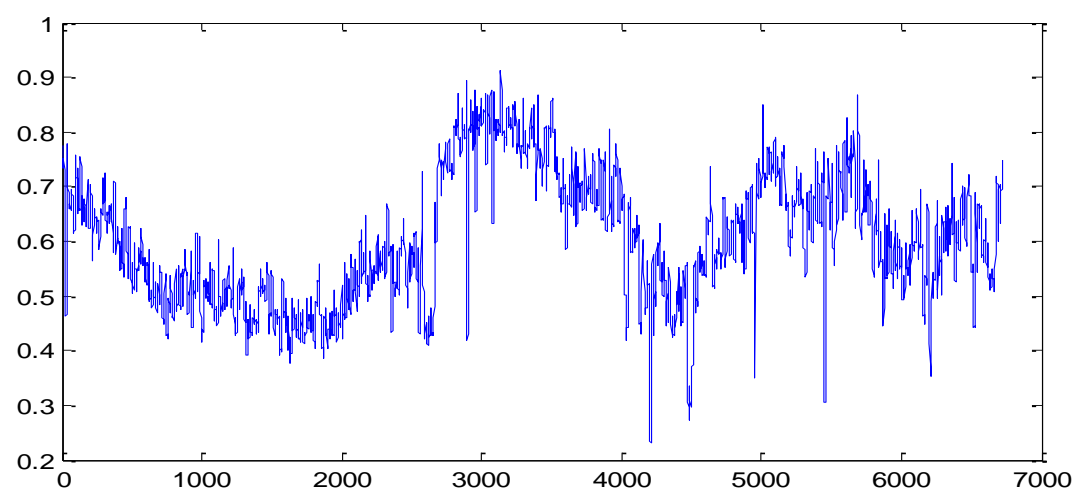

Table 20. Results of the estimation of $\mathrm{H}$ for Syria

The Hurst Plot of $\mathrm{H}$

Exponent

SYP/EUR

$H_{\text {IRS }}=0.25$

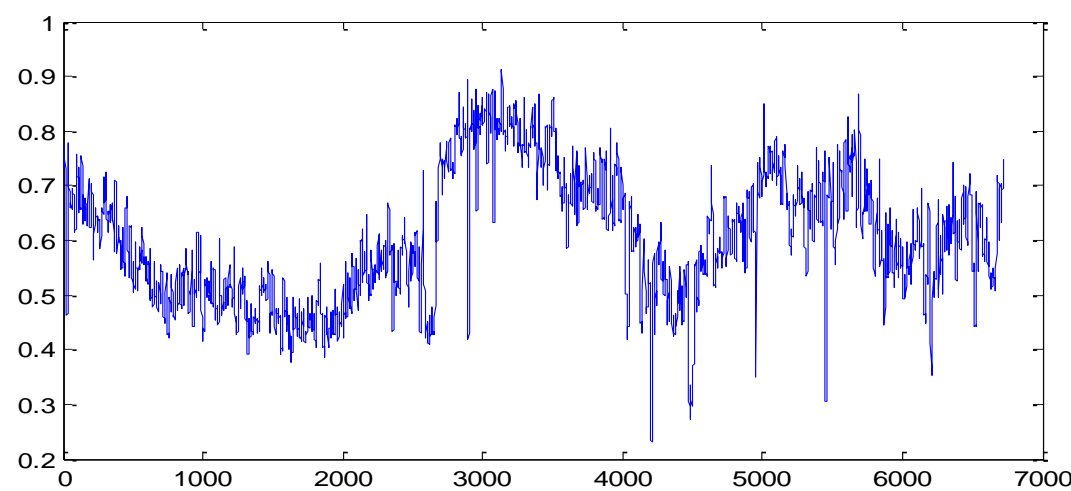


Table 21. Results of the estimation of $\mathrm{H}$ for Tunisia

\begin{tabular}{lll}
\hline The Hurst & Plot of $\mathrm{H}$ \\
Exponent & & \\
\hline
\end{tabular}

\section{TND/EUR}

$H_{\text {IRS }}=0.57$

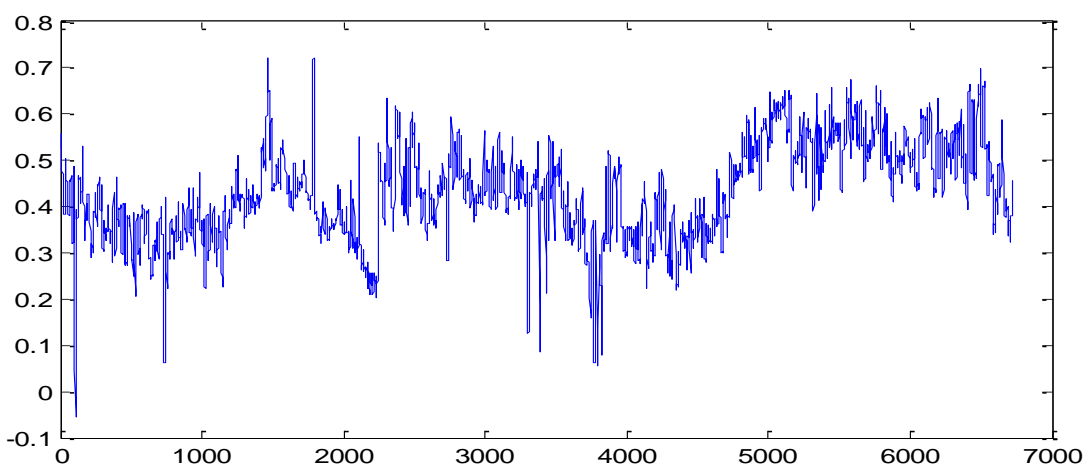

\section{Conclusion}

The fractal approach, in economic modeling, is still in an exploratory phase with nevertheless clear advances over the past decade since the classic hypothesis in economics is that of a homogeneous market. While the different market hypothesis is a new idea in foreign exchange market modeling, it appears that agents have different risk profiles, geographical locations and institutional constraints.

The purpose of this paper was to expose the tools of multifractal formalization in order to present the FMH to examine the behavior of currency markets for MENA countries. This study has shown that a phenomenon of multifractality characterizes the series of exchange rates against the euro. We first estimated the partition function and scaling function of each series and then the Hurst exponent associated by two methods namely, the Generalized Quadratic Variations (GQV) method and the Increment Ratio Statistic (IRS) method. From this, we deduce the FMH of currency markets against the euro for the MENA countries. As well, multifractal modeling offers a new framework for studying exchange rate series that are very promising and open new perspectives on the forecasting approach of economic series.

\section{Acknowledgements}

We thank the Editorial Team and anonymous reviewers for their helpful comments.

\section{References}

Ayache, A., \& Taqqu, M. S. (2005). Multifractional Processes With Random Exponent. Publ Mat, 49(2), $459-486$. https://doi.org/10.5565/PUBLMAT_49205_11

Bardet, J. M., \& Surgailis, D. (2008). Measuring the roughness of random paths by increment ratios. hal-00238556, version 1-4. https://doi.org/10.3150/10-BEJ291

Benassi, A., Jaffard, S., \& Roux, D. (1997). Elliptic Gaussian Random Processes, RevMat Iberoam, 13(1), 19-90. https://doi.org/10.4171/RMI/217

Bertrand, P. R., Hamdouni, A., Haouas, N., \& Khadraoui, S. (2010). Modélisation d'une Série Financière par Mouvement Brownien Multifractionnaire Parcimonieux, In 42èmes Journées de Statistique. HAL Id: inria-00502144. https://hal.inria.fr/inria-00502144

Calvet, L., Adlai, F., \& Mandelbrot, B. (1997). Multifractality of Deutschemark/US Dollar Exchange Rates. Cowles Foundation Discussion Papers, 1166.

Calvet, L., \& Fisher, A. (2002). Multifractality in asset returns: Theory and evidence. The Review of Economics and Statistics, 84(3), 381-406. https://doi.org/10.1162/003465302320259420

Coeurjolly, J. F. (2001). Estimating the parameters of a fractional brownian motion by discrete variations of its sample paths. Statistical Inference for Stochastic Processes, 4(2), 199-227. https://doi.org/10.1023/A:1017507306245

Fama, E. (1965). The Behavior of Stock Market Prices, Journal of Business, 38, 34-105. 
https://doi.org/10.1086/294743

Fama, E. (1970). Efficient Capital Markets: A Review of Theory and Empirical Work, Journal of Finance, 25 , 383-417. https://doi.org/10.1111/j.1540-6261.1970.tb00518.x

Fama, E. (1991). Efficient Capital Markets: II, Journal of Finance, 46, 1575-1618. https://doi.org/10.2307/2328565

Fillol, J. (2003). Multifractality: Theory and evidence. An application to the french stock market, Economics Bulletin, 3(31), 1-12. http://www.accessecon.com/pubs/EB/2003/Volume3/EB-03C50005A.pdf

Guasoni, P., Rásonyi, M., \& Schachermayer, W. (2008). The Fundamental Theorem of Asset Pricing for Continuous Processes Under Small Transaction Costs. Ann Finance. https://doi.org/10.1007/s10436-008-0110-X

Istas, J., \& Lang, G. (1997). Quadratic Variations and Estimation of the Local Hölder Index of a Gaussian Process, Ann Inst Poincaré, 33, 407-436. https://doi.org/10.1016/S0246-0203(97)80099-4

Jensen, M. C. (1978). Some Anomalous Evidence Regarding Market Efficiency. Journal of Financial Economics, 6, 95-101. https://doi.org/10.1016/0304-405X(78)90025-9

Lim, K. P., \& Brooks, R. (2011). The Evolution of Stock Market Efficiency Over Time: A Survey of the Empirical Literature. Journal of Economic Surveys, 25, 69-108. https://doi.org/10.1111/j.1467-6419.2009.00611.x

Malkiel, B. G. (1973). A Random Walk Down Wall Street. W. W. Norton \& Company.

Malkiel, B. G. (2003). The Efficient Market Hypothesis and Its Critics. Journal of Economic Perspectives, 17(1), 59-82. https://doi.org/ 10.1257/089533003321164958

Mandelbrot, B., \& Van-Ness, J. (1968). Fractional Brownian motion, Fractional Noises and Applications, SIAM Rev, 10, 422-437. https://doi.org/10.1137/1010093

Mandelbrot, B. (1997). Fractals and Scaling in Finance: Discontinuity, Concentration, Risk. Springer Verlag. https://doi.org/10.1007/978-1-4757-2763-0

Onali, E., \& Goddard, J. (2009). Unifractality and multifractality in the Italian stock market. International Review of Financial Analysis, 18(4), 154-163. https://doi.org/10.1016/j.irfa.2009.05.001

Onali, E., \& Goddard, J. (2011). Are European equity markets efficient? New evidence from fractal analysis. International Review of Financial Analysis, 20(2), 59-67.https://doi.org/10.1016/j.irfa.2011.02.004

Peltier, R., \& Lévy-Véhel, J. (1995). Multifractional Brownian motion: Definition and Preliminary Results, Rapport technique INRIA.

Peters, E. (1994). Fractal Market Analysis: Applying Chaos Theory to Investment and Analysis. John Wiley \& Sons.

Shleifer, A. (2010). Inefficient Markets: An Introduction to Behavioural Finance. OUP Oxford.

Um, J. U. (1999). Investigating the Multifractal Model of Asset Returns. Kungl Tekniska Högskolan.

Yen, G., \& Lee, C. (2008). Efficient Market Hypothesis (EMH): Past, Present and Future. Review of Pacific Basin Financial Markets and Policie, 11, 305-329. https://doi.org/10.1142/S0219091508001362

\section{Copyrights}

Copyright for this article is retained by the author(s), with first publication rights granted to the journal.

This is an open-access article distributed under the terms and conditions of the Creative Commons Attribution license (http://creativecommons.org/licenses/by/4.0/). 